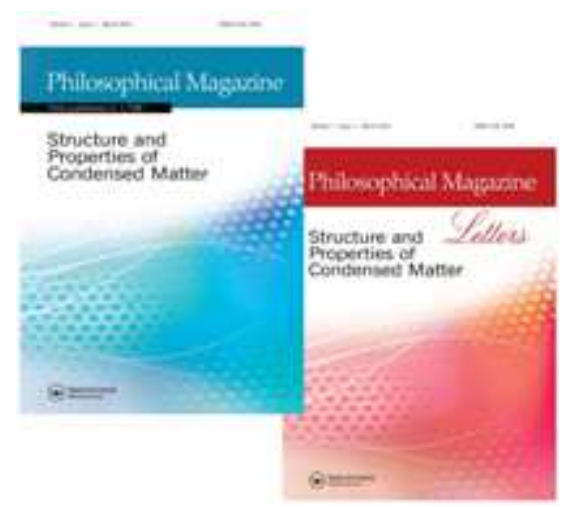

\title{
High-temperature creep of single-crystal nickel-based superalloy: microstructural changes and effects of thermal cycling.
}

\begin{tabular}{|c|c|}
\hline Journal: & Philosophical Magazine \& Philosophical Magazine Letters \\
\hline Manuscript ID: & TPHM-11-Apr-0142.R1 \\
\hline Journal Selection: & Philosophical Magazine \\
\hline $\begin{array}{l}\text { Date Submitted by the } \\
\text { Author: }\end{array}$ & 20-Jul-2011 \\
\hline Complete List of Authors: & $\begin{array}{l}\text { VIGUIER, Bernard; Université de Toulouse, CIRIMAT - } \\
\text { INP/ENSIACET } \\
\text { Touratier, Fabienne; Université de Toulouse, CIRIMAT - } \\
\text { INP/ENSIACET } \\
\text { Andrieu, E.; Université de Toulouse, CIRIMAT - INP/ENSIACET }\end{array}$ \\
\hline Keywords: & $\begin{array}{l}\mathrm{Ni} \text {-based superalloys, dislocation mechanics, precipitation, } \\
\text { microstructure change }\end{array}$ \\
\hline Keywords (user supplied): & climb \\
\hline
\end{tabular}

\section{SCHOLARONE" \\ Manuscripts}




\begin{abstract}
Creep tests have been performed on $\mathrm{MC} 2$ single crystal superalloy at $950^{\circ} \mathrm{C} / 200 \mathrm{MPa}$ and $1150^{\circ} \mathrm{C} / 80 \mathrm{MPa}$ under isothermal and thermal cycling conditions with a tensile axis along the [001] direction. It is shown that the thermal cycles strongly affect the creep behaviour at $1150^{\circ} \mathrm{C}$ but not at $950^{\circ} \mathrm{C}$. This was related to the repetitive precipitation and dissolution of $\gamma^{\prime}$ small rafts for the higher temperature, as revealed by quantitative characterisation of the $\gamma / \gamma^{\prime}$ microstructure. The dislocation microstructure exhibits similar trends in all the tested conditions, with a very high activity of a[100]-type dislocations climbing through the rafts. Such climbing dislocations constitute a recovery process for the deformation active system. It appeared that the density of a[100] dislocations, and not their climb velocity - or diffusion rate - is the key parameter for the control of creep rate. The thermal cycles which imply the creation and subsequent dissolution of rafts, provided new dislocations which explains the acceleration of creep observed under such conditions.
\end{abstract}

Keywords: anisothermal, creep, superalloy, MC2, climb, dislocations, rafting

\title{
1. Introduction
}

Single-crystal nickel-based superalloys are extensively used in the aeronautic

industry, particularly in the hottest parts of turbo-reactors for aircraft and helicopters.

The optimized microstructure consists of an array of $\gamma^{\prime}$ cubic precipitates aligned along the $<100>$ cubic directions and coherently embedded in an austenitic matrix $\gamma$. Creep at high temperature leads to changes in this microstructure where cubes coarsen to form platelets in a direction perpendicular to the [001] tensile axis depending on the sign of the misfit: this is rafting [1]. The creep behavior of superalloys and the associated morphological changes have been extensively studied over the last 30 years but almost exclusively by means of isothermal creep tests [2-5]. Real service conditions in aircraft or helicopter engines, including certification tests, imply much 
to be submitted to Phil Mag.

more severe thermo-mechanical loading of the superalloys, far from isothermal and where temperatures can reach up to $1200^{\circ} \mathrm{C}$ during emergency regimes. Nevertheless, very few studies have dealt with non isothermal creep [6-10]. Raffaitin et al. [6, 7] studied the behavior of the superalloy MC2 with anisothermal creep at very high temperatures. During thermal cycling creep tests under $1150^{\circ} \mathrm{C}$ and $80 \mathrm{MPa}$, with cycles composed of heating, high-temperature dwell and cooling steps, they reported a creep behavior drastically different from that observed under isothermal loading, reducing creep life 3 - or 4-fold and increasing the secondary creep rate 10-fold. Besides, a focus on the strain corresponding to each cycle underlines that it is not linear but shows, at the beginning of the high-temperature dwell, a transient period followed by a linear phase. This acceleration recalling a primary creep stage involves the acceleration of the global creep rate; however, its origin has not yet been fully elucidated.

Superalloy high-temperature isothermal creep is being increasingly studied and results show the presence of $\mathrm{a}<010>$ prismatic edge dislocations aligned along $<110>$ directions and moving by climb within the rafts [11-20]. It has been observed that the majority of these systems are a[100] or a[010] dislocations, so they experience no force at all from the [001] applied stress (their Schmid factor for glide and climb is equal to 0 ). One way to explain climbing of such systems into the rafts was proposed by Epishin et al. [16]. Their model consists in a vacancy exchange between two different dislocation systems, moving by pure climb or by a combined glide and climb process: the first is localized at the $\gamma / \gamma^{\prime}$ interface, takes part in the interfacial network, and is composed of a[001] dislocations activated by the applied stress, while the second is composed of $\mathrm{a}[100]$ and $\mathrm{a}[010]$ dislocations, fed by the vacancies from the first system. This mechanism was also investigated by Mompiou 
and Caillard to explain quasi-crystal deformation [21, 22]. The climbing of a[100] type dislocations does not produce a creep strain along the load axis directly, but it is an essential sequence of the global deformation mechanism occurring during the secondary stage of nickel-based superalloy creep. Indeed when the superalloy microstructure is fully rafted, the deformation can be limited to the $\gamma$ corridors otherwise dislocations would accumulate at the $\gamma / \gamma^{\prime}$ interface and strain would be rapidly stopped. Steady-state deformation requires a recovery process for the annihilation of the accumulated dislocations, which implies that the $\gamma^{\prime}$ rafts must be crossed. The climb of [010] dislocations, even if it does not produce any deformation along the [001] axis, can be considered as the limiting step of the global creep mechanism.

The present study aims at improving our understanding of the fundamental mechanisms occurring during high-temperature creep of single-crystal superalloys. We focused our study on two scale levels. First the evolution of the $\gamma / \gamma^{\prime}$ microstructure is studied during the creep tests with an emphasis on the changes occurring during the imposed thermal cycle. Then the active dislocation systems are characterized in order to elucidate the creep rate-controlling mechanism. Finally, the high-temperature mechanisms will be discussed with regard to these results and the consequences of thermal cycling conditions upon dislocation mechanism will be examined.

\section{Experimental details}

The material for this study was the single crystal nickel-based superalloy MC2 (nominal composition in wt. \% Ni-7.2Cr-8Co-2Mo-7W-5.5Al-1.3Ti-5.6Ta) provided 
to be submitted to Phil Mag.

by Turbomeca in the form of a single crystal plate subjected to the standard solutioning treatment: $3 \mathrm{~h}$ at $1300^{\circ} \mathrm{C}$. Flat thin-wall tensile creep specimens $(3 \times 20$ $\mathrm{mm}^{2}$ gage length, $1 \mathrm{~mm}$ thick) were electro-discharge machined with the long axis of the specimen along the [001] direction while the flat face was parallel to the (100) plane. After cutting, the specimens were heat treated for $6 \mathrm{~h}$ at $1080^{\circ} \mathrm{C}$ followed by air cooling and $20 \mathrm{~h}$ at $870^{\circ} \mathrm{C}$ then final air cooling. All the faces of the creep specimens were ground with $\mathrm{SiC}$ paper, down to grade 4000 for the two large faces and grade 1000 for the edges, in order to remove the electro-discharge machine damaged zone. It was checked that the initial microstructure consisted of cubic $\gamma^{\prime}$ precipitates (with a $440 \mathrm{~nm}$ mean edge length), well aligned along the $<001>$ directions in the $\gamma$ austenitic matrix. Creep tests were performed at $950^{\circ} \mathrm{C} / 200 \mathrm{MPa}$ and at $1150^{\circ} \mathrm{C} / 80 \mathrm{MPa}$ along the [001] direction under laboratory air on a creep frame loaded with a dead weight (i.e. constant load conditions) equipped with a radiation furnace allowing fast temperature changes. Isothermal and thermal cycling creep was studied, in both cases the specimen was first heated to the high-temperature value (either 950 or $1150^{\circ} \mathrm{C}$ ) and then loaded by setting the required weight. The deformation was recorded using a contact-less laser extensometer as described in detail in [23]. For thermal cycling creep experiments, the temperature was monitored as shown in Figure 1: the cycle duration was 60 minutes with a 5 minute heating stage up to 950 or $1150^{\circ} \mathrm{C}$, a dwell time of 30 minutes and a 25 minutes cooling stage (see below for the temperature profile during the cooling step) down to about $45^{\circ} \mathrm{C}$. The load was kept constant during the thermal cycling.

Special care was taken in the way specimens were cooled for the interrupted tests. Indeed, this is of prime importance in order to get information on the evolution of the $\gamma / \gamma^{\prime}$ microstructure and specially the $\gamma^{\prime}$ dissolution phenomenon. First, we shall 
consider the cooling rate that the sample experiences during the normal thermal cycle. This is shown as the "slow" rate curve in Figure 2, it corresponds to a controlled cooling rate of $3.75^{\circ} \mathrm{C} / \mathrm{s}$ down to $600^{\circ} \mathrm{C}$ and then an even slower cooling rate due to the furnace and load train thermal inertia. Some creep experiments were interrupted at the end of such cooling steps for microstructure observations which are representative of the low temperature state during the thermal cycle (point B in Figure1). Secondly, some specimens were cooled as fast as possible, by suddenly switching off the radiation furnace and opening the specimen chamber, so that the specimen is cooled directly by laboratory air flow. This is illustrated by the "quench" curve in Figure 2, and corresponds to a cooling rate of $33^{\circ} \mathrm{C} / \mathrm{s}$ down to $800^{\circ} \mathrm{C}$ (the specimen cooled from 1150 to $850^{\circ} \mathrm{C}$ in $9 \mathrm{~s}$ ). This cooling procedure was applied at the end and at the beginning of the high-temperature dwell of the thermal cycles (points A and C respectively in Figure 1). Finally some specimens were also cooled by switching off the radiation furnace and letting the specimen cool down in the furnace, this gave an intermediate cooling rate, labelled "fast" in Figure 2 and which was mainly used for isothermal creep tests. After the creep tests, the specimens were mechanically ground, first with SiC paper, then with diamond paste down to $1 \mu \mathrm{m}$ and finally etched with an electrolytic solution $\left(13 \% \mathrm{H}_{3} \mathrm{PO}_{4}, 45 \% \mathrm{H}_{2} \mathrm{SO}_{4}\right.$ and $42 \% \mathrm{HNO}_{3}$ under $\left.3 \mathrm{~V}\right)$ allowing $\gamma$ matrix dissolution. Scanning electron microscopy (SEM) was performed with a JEOL JSM $6700 \mathrm{~F}$ equipped with a field emission gun operating at $15 \mathrm{kV}$ using secondary electron mode. The observations were made on the flat surface of the creep specimen. In all SEM images reported the tensile axis [001] is vertical in the image plane - (100) plane. Quantitative data on the $\gamma^{\prime}$ raft morphology were obtained using image analysis of the SEM micrographs by Image J software [24]. The surface fraction of the rafts was determined by manually redrawing the contour of rafts on seven images for each 
to be submitted to Phil Mag.

experiment. Note that only rafts were considered, not the secondary precipitates neither in spherical nor in cuboid shape. The thickness of the rafts and the periodicity of the structure were measured along intercept lines drawn parallel to the [001] direction, more details on such measurements are given in [25].

Thin foils for transmission electron microscopy (TEM) were sawn from thin wall creep samples as squares $2.1 \mathrm{~mm}$ in length and $200 \mu \mathrm{m}$ in thickness. These slices were then mechanically polished down to about $50 \mu \mathrm{m}$ while tilted in order to achieve an orientation of the slice close to (211). The foils were then dimpled to about $20 \mu \mathrm{m}$ and ion milled using a Gatan PIPS ® system. Dislocation observations for further indexation were achieved in two-beam diffraction contrast on a Jeol 2010 operating at $200 \mathrm{kV}$ at the TEMSCAN Service of University Paul Sabatier in Toulouse.

\section{Results}

\subsection{Mechanical behaviour}

The results of creep tests performed at $950^{\circ} \mathrm{C} / 200 \mathrm{MPa}$ and $1150^{\circ} \mathrm{C} / 80 \mathrm{MPa}$ are shown in Figure 3 for isothermal and thermal cycling conditions. With thermal cycling, the curves show only the deformation accumulated during the hightemperature dwell, following the procedure described by Raffaitin et al. [6]. As reported in Figure 3, the thermal cycling strongly affects the creep resistance at $1150^{\circ} \mathrm{C}$, with a significant increase of the secondary creep rate and reduction of the creep life duration. The average secondary creep rate increases from $7.510^{-8} \mathrm{~s}^{-1}$ for isothermal conditions to $410^{-7} \mathrm{~s}^{-1}$ in the present anisothermal creep conditions. As already noted [6] the strain produced during each high-temperature dwell is not a linear function of the time but instead presents a slope change analogous to primary secondary creep stages as illustrated in Figure 4.a. The occurrence of this primary 
stage for each cycle is believed to be responsible for the global creep acceleration. Similar behaviour and the same occurrence of primary creep after a thermal change was also reported by Cormier et al [9]. For comparison, isothermal and thermal cycling creep experiments were conducted at $950^{\circ} \mathrm{C}$, under $200 \mathrm{MPa}$. Due to the very long creep life in those conditions the tests were not conducted to rupture but stopped during the secondary stage. The curves shown in Figure 3 indicate that, for $950^{\circ} \mathrm{C}$, the thermal cycling did not affect the secondary creep rate. Indeed the same average secondary creep rate $\left(10^{-8} \mathrm{~s}^{-1}\right)$ was measured for isothermal and anisothermal conditions. Furthermore close examination of the deformation curve of the thermal cycling creep test shows that for each high-temperature dwell, the strain is a linear function of time (constant creep rate), see Figure 4.b, unlike the primary and secondary stages observed for thermal cycling creep at $1150^{\circ} \mathrm{C}$. This observation supports the link between the global creep acceleration due to thermal cycling at $1150^{\circ} \mathrm{C}$ and the occurrence of a primary creep stage for each dwell.

\subsection{Microstructural characterisation}

\subsection{1 $\gamma / \gamma^{\prime}$ microstructure evolution}

The microstructure of the crept specimens was investigated firstly at the $\gamma / \gamma^{\prime}$ scale (SEM observations). Figure 5 shows the microstructure of specimens tested at $950^{\circ} \mathrm{C}$ under isothermal and thermal cycling conditions, and interrupted after 117 and 147 hours respectively (time at high temperature). After creep interruption, the isothermal sample was cooled using the "fast" procedure and the thermal cycling test was interrupted at the low-temperature state of the cycle (corresponding to point B in Figure 1). The microstructures showed a very clear rafted state as commonly observed in the secondary creep stage [1]. Quantitative image analyses reveal a surface fraction of the $\gamma^{\prime}$ phase of 75 and $73.5 \%$ and raft thickness of $420 \pm 20$ and $405 \pm 25 \mathrm{~nm}$ for 
to be submitted to Phil Mag.

the isothermal and thermally cycled specimens respectively. Those values correspond to a classical rafted structure in MC2 alloy under tensile creep at temperatures lower than $1000^{\circ} \mathrm{C}$. They indicate that $\gamma^{\prime}$ dissolution does not occur during exposure to $950^{\circ} \mathrm{C}$ whether in isothermal or cycling conditions.

In contrast, the microstructures observed on specimens crept at $1150^{\circ} \mathrm{C}$ under isothermal figure 6(a) and thermal cycling tests figures 6(b to d) interrupted at different points of the thermal cycle are quite different. The thermal cycling creep tests were interrupted at the end of the $12^{\text {th }}$ - beginning of $13^{\text {th }}$ cycle, as schematised in Figure 1. The first specimen, shown in Figure 6(b), corresponds to the interruption of the test at the end of the $12^{\text {th }}$ with a "quench" cooling; it is representative of point A in Figure 1. The second specimen, Figure 6(c), also stopped at the end the $12^{\text {th }}$ cycle, was cooled with the "slow" procedure and thus represents low-temperature point - B - of the thermal cycle. Finally the microstructure seen in Figure 6(d) is from a sample that was "quenched" from the beginning of the $13^{\text {th }}$ thermal cycle and represents point $\mathrm{C}$. These three specimens spent the same time ( 6 hours) at $1150^{\circ} \mathrm{C}$ and experienced about $1 \%$ creep strain. For comparison the isothermal specimen, shown in Figure 6(a), was also stopped after 1\% creep strain, which in this case corresponds to 14 hours spent at $1150^{\circ} \mathrm{C}$. The general and common feature of the microstructures observed in Figure 6 is the presence of large $\gamma^{\prime}$ precipitates - the rafts - associated with smaller ones - secondary precipitates - within the $\gamma$ corridors. It is also apparently evident that the surface fraction of the rafts is much smaller than after creep at $950^{\circ} \mathrm{C}$. These observations indicate the role of $\gamma^{\prime}$ dissolution during creep at $1150^{\circ} \mathrm{C}$, indeed for such temperatures the equilibrium volume fraction of $\gamma^{\prime}$ decreased significantly [8]. A much more precise comparison of these microstructures was obtained by quantitatively measuring the raft characteristics, in terms of raft surface 
fraction $\left(f_{\mathrm{sR}}\right)$, raft thickness $(t)$ and periodicity of the $\gamma / \gamma^{\prime}$ sequence $(\lambda)$. The results of these measurements, listed in Table 1, clearly reveal two main features: firstly a difference between the isothermal and the anisothermal microstructures, and secondly, an evolution of the microstructure during one thermal cycle. The most important microstructural difference between isothermal and anisothermal creep concerns the surface fraction of the rafts which was significantly lower for the anisothermal creep $\left(f_{s R}=40-47 \%\right)$ than for the isothermal $\left(f_{s R}=56 \%\right)$, despite the fact that anisothermal specimens spent less time at $1150^{\circ} \mathrm{C}$ than isothermal specimens. The surface fraction of rafts also changed during one thermal cycle, since it rose from about $40 \%$ for the high-temperature states (40\% for point $\mathrm{A}$ and $42 \%$ for C) to $47 \%$ for the low-temperature point $B$. This variation of raft surface fraction already indicates that the thermal cycling enhanced the dissolution of $\gamma^{\prime}$ rafts, and that during cycling, rafts continuously dissolved and reprecipitated. It also appears that the raft thickness depends on the creep conditions. Indeed, after isothermal creep the average thickness of the rafts was $t=410 \mathrm{~nm}$, the same value was measured after thermal cycling was interrupted at point $\mathrm{C}$ (beginning of the high-temperature dwell during cycling creep) whereas the thickness was slightly lower for the lowtemperature point $(t=400 \mathrm{~nm}$ for point $\mathrm{B})$ and significantly lower at the end of the dwell $(t=356 \mathrm{~nm}$ for point A). The parameter $\lambda$ also varied during the thermal cycle: $\lambda=908 \mathrm{~nm}$ at the end of the dwell - point A - it dropped to $690 \mathrm{~nm}$ for the lowtemperature point $-\mathrm{B}$ - and increased back to $805 \mathrm{~nm}$ at the beginning of the following dwell - point $\mathrm{C}$. This parameter is correlated to the number of rafts present in the microstructure, and its variations thus show that rafts are successively created and dissolved during the thermal cycle. 
to be submitted to Phil Mag.

Besides the variation of raft structure, secondary $\gamma^{\prime}$ precipitates are visible in the micrographs of Figure 6 in the $\gamma$ matrix channels. These small precipitates are due to $\gamma^{\prime}$ phase dissolution during the high-temperature dwell and its re-precipitation during the cooling phase as is currently reported in the literature [26-28]. These secondary precipitates exhibit different morphologies and sizes, mainly depending on the cooling rate as shown in Figure 7. For rapid cooling, such as "quench" and "fast" procedures, the secondary precipitation consists in the homogeneous distribution of spherical precipitates with a diameter of around $30 \mathrm{~nm}$, as exemplified in Figure 7(a). For the "slow" cooling rate, corresponding to point B in the thermal cycle, secondary precipitation forms cuboid precipitates with a mean edge length of $100 \mathrm{~nm}$. Unlike the spheres, these cubes are not homogeneously distributed in the $\gamma$ channels but are concentrated in the middle of the channel and surrounded by the $\gamma$ phase containing fine spherical precipitates with $23 \mathrm{~nm}$ mean diameter Figure 7(b). Examination of the microstructure at a larger scale in the B state also reveals that some of the cuboid secondary precipitates coalesced to form new rafts, in agreement with the decrease of the period $\lambda$ which was measured between states $A$ and $B$.

If we now summarise the overall change of the $\gamma^{\prime}$ precipitates during a cycle of an anisothermal creep test at $1150^{\circ} \mathrm{C}$, it can be noticed that during the cooling phase (A to B) the thickness of the rafts increased, the period of the structure decreased considerably and as a consequence, the surface fraction of the rafts increased. During the heating phase (B to C), the thickness of the rafts remained constant, the period of the structure increased but remained below the value of the state A and the surface fraction of the rafts decreased slightly. Finally, on the hightemperature dwell (C to A), the thickness of the rafts decreased, the period of the 
structure increased and so, the surface fraction decreased. This will be discussed below in terms of dissolution and reprecipitation of the $\gamma^{\prime}$ rafts and its consequences on the creep behaviour during thermal cycling creep tests.

\subsubsection{Dislocation microstructures}

Dislocation microstructures were observed in the specimens crept in the different conditions. Since we are working with rafted structures, recovery mechanisms of the $\gamma$ dislocations are required to allow macroscopic deformation of the superalloy. It has been repeatedly proposed that such recovery may occur by dislocations crossing the $\gamma^{\prime}$ rafts $[29,30]$. Thus, we focus our study on the dislocation microstructure within the rafts. A view of the dislocation landscape after creep under thermal cycling conditions at $950^{\circ} \mathrm{C} / 200 \mathrm{MPa}$ is shown in Figure 8 . It is seen that $\gamma$ channels contain only a few dislocations (with a $\frac{1}{2}[110]$ type Burgers vector) related to interfacial dislocations. In contrast, quite numerous, isolated dislocations can be seen in the $\gamma^{\prime}$ rafts. They either go right across the rafts (dislocation 1 in Figure 8) or they form loops connected to one side of the raft and which bow into the $\gamma^{\prime}$ raft (dislocation 2 in Figure 8). Similar configurations were observed in specimens crept under isothermal conditions. A more detailed analysis of different dislocation segments was performed on a specimen crept under isothermal conditions at $1150^{\circ} \mathrm{C} / 80 \mathrm{MPa}$. Figure 9 shows images of the same area obtained with two different diffraction vectors. The whole analysis required the use of up to seven different diffraction vectors; the direction of different dislocation segments was determined using trace analysis on the foil stereographic projection. Note that this analysis was made more complex by the fact that for dislocations with Burgers vectors of the type $\mathrm{a}[010]$ the $\mathbf{g} \cdot \mathbf{b}=0$ criterion is not sufficient and quite a 
to be submitted to Phil Mag.

strong residual contrast occurs when $\mathbf{g . b} \wedge \xi \neq 0$ as shown previously in the literature

$[15,31]$. The results of such analysis are shown in Table 2 , showing that the

dislocations present within the $\gamma^{\prime}$ raft have a[010] Burgers vector. Their line segment

is often parallel to $<101>$ directions, so they are edge or $45^{\circ}$ mixed dislocations.

Moreover, spatial configuration of dislocations, such as the segments labelled 4, 5 and

6 in Figure 9 show that they do not lie in their glide plane as showed in the scheme in

Figure 9.c. Such a spatial configuration could only be obtained by an intensive climb

process. A more general view of the dislocation landscape is shown in Figure 10, for a

specimen crept at $1150^{\circ} \mathrm{C} / 80 \mathrm{MPa}$ under cycling conditions (the test was interrupted

after about $1 \%$ strain at point B - low temperature of the cycle). Results of similar

analysis performed on the different creep conditions show that, for all the creep

conditions that were studied (isothermal or anisothermal at $1150^{\circ} \mathrm{C}$ and $950^{\circ} \mathrm{C}$ ), the

same type of dislocations was present within the rafts. They mainly consisted of

$\mathrm{a}[100]$ or $\mathrm{a}[010]$ edges or $45^{\circ}$ dislocations aligned along the $<101>$ directions and

sometimes some $\mathrm{a} / 2<110>$ dislocations in the $\gamma$ corridors, mainly at $950^{\circ} \mathrm{C}$. For

$1150^{\circ} \mathrm{C} / 80 \mathrm{MPa}$ conditions, the shape of these dislocations is prismatic with very

straight segments (Figures 9 and 10) whereas for $950^{\circ} \mathrm{C} / 200 \mathrm{MPa}$, they are either

straight or rounded (Figure 8). Evidence of spatial configurations resulting from climb

was observed for all the conditions examined. We reported in Table the results of

rough estimate of the dislocation densities (based on the projected length of

dislocation lines in TEM micrograph without considering the projection correction

due to the different line orientations). It appears that a[010] type dislocations make up not quite half of the total dislocations observed after creep at $950^{\circ} \mathrm{C}$ under cyclic

conditions whereas they were the more numerous after creep at $1150^{\circ} \mathrm{C}$, especially for creep under anisothermal conditions (this estimation does not take into account the 
$\gamma / \gamma^{\prime}$ interfacial dislocations). Such measurements show the importance of climb of $\mathrm{a}[010]$ dislocations during creep of the superalloy at such high temperatures.

\section{Discussion}

The creep behaviour of MC2 single crystal superalloy was studied at 950 and $1150^{\circ} \mathrm{C}$ under isothermal and thermal cycling conditions. We showed that thermal cycling has a tremendous effect on creep properties at $1150^{\circ} \mathrm{C}$, with an acceleration of creep strain and reduction of life-time, while the creep curves on each high-temperature dwell exhibit a succession of primary and secondary creep stages. In contrast, the creep rate does not seem to be affected by thermal cycling at $950^{\circ} \mathrm{C}$ and the individual creep steps during high-temperature dwell show a monotonous increase of strain with time (steady - state type creep). Two microstructural phenomena revealed in the present study may play a significant role on creep behaviour at such high temperatures. These are i) the evolution of $\gamma^{\prime}$ precipitates with dissolution-reprecipitation and ii) the climb of $\mathbf{b}=\mathbf{a}<010>$ dislocations within the $\gamma^{\prime}$ rafts.

\subsection{Dissolution / reprecipitation of $\gamma$ 'phase}

The changes that occur in the $\gamma / \gamma^{\prime}$ microstructure during high-temperature creep is of prime importance. The rafting phenomenon that transforms the initial cuboid precipitate morphology into large plates has been studied for a many years $[1$, 3]. For moderate temperatures, as is the case in the present study for creep at $950^{\circ} \mathrm{C}$, this rafting occurs at constant $\gamma^{\prime}$ volume fraction as compared to the initial state. Only very severe plastic deformation leads to destabilisation of the rafts during the tertiary stage of the creep curve [32, 33]. However, for higher temperatures as is the case in the present study of creep at $1150^{\circ} \mathrm{C}$, dissolution of the $\gamma^{\prime}$ phase may occur $[8,34]$. 
to be submitted to Phil Mag.

The first evidence of $\gamma^{\prime}$ dissolution is given by the values of the raft surface fraction. Indeed in the initial microstructure, the surface fraction of $\gamma^{\prime}$ cuboids is about $70 \%$. This surface fraction does not change significantly after creep at $950^{\circ} \mathrm{C}$ either under isothermal or cycling conditions. In contrast, creep at $1150^{\circ} \mathrm{C}$ involves a decrease of the surface fraction down to $56 \%$ for isothermal conditions and down to about $40 \%$ for thermal cycling creep. A direct consequence of $\gamma^{\prime}$ dissolution is to create a supersaturated $\gamma$ matrix that will lead to the formation of fine $\gamma$ ' secondary precipitates upon cooling [35], such as those visible within the $\gamma$ channels in the micrographs in Figure 6. It is striking to observe the influence of the cooling rate on secondary precipitate morphology as shown in Figure 7. Indeed the only difference between samples A and B is the cooling rate: "quench" for A and "slow" for B, according to the notation used in Figure 2. This precipitation has huge consequences on the way the microstructure changes, since precipitation during the slow cooling steps of the thermal cycles involves the creation of new small rafts as discussed below.

From the microstructural study and the morphological data (Table 1) extracted from interrupted thermal creep tests $\mathrm{A}, \mathrm{B}$ and $\mathrm{C}$ at $1150^{\circ} \mathrm{C} / 80 \mathrm{MPa}$, we can propose the following microstructural alterations during one thermal cycle. From A to B, this is the slow rate cooling step, the period $\lambda$ of the rafted structure significantly decreased (from 910 to $690 \mathrm{~nm}$ ) which means that new rafts appeared in the matrix corridors. The new rafts were created during cooling by the coalescence of the cubic secondary precipitates of the $\gamma^{\prime}$ phase, as observed in Figure 7(b). It is notable that the new rafts are created very rapidly, since the time necessary to decrease the temperature from 1150 to $900^{\circ} \mathrm{C}$ is less than $90 \mathrm{~s}$. From B to C, when the temperature was increased from room temperature to $1150^{\circ} \mathrm{C}$, the period of the structure increased (but $\lambda$ is 
lower at point $\mathrm{C}$ than it is at point $\mathrm{A}$ ) which means that only one part of the rafts - the smallest - formed during the cooling phase dissolved during reheating. This dissolution of the smaller fresh rafts is supported by the complete dissolution of cuboid secondary precipitates which is visible when comparing Figures 6(c) and 6(d). This dissolution of the thinner rafts resulted in the cut off of the size distribution of raft thickness for the smaller values which implied an increase of the mean value of the distribution. Indeed during this heating step, the mean thickness of the rafts increased slightly from $400 \mathrm{~nm}$ (point B at room temperature) to $410 \mathrm{~nm}$ (point C at $\left.1150^{\circ} \mathrm{C}\right)$. It is even possible that during this step the thicker rafts were moderately eroded but to a less extend than the small ones. This highlights the stability of the larger rafts probably related to a very well established interfacial dislocation network. Indeed the interfacial dislocation network does not appear to evolve along the thermal cycle [36]. During the temperature dwell of the thermal cycle (from C to A), we can note that the thickness of the rafts decreased and that the period of the structure increased which means that the small rafts formed during the cooling step were totally dissolved and that the larger ones began to dissolve slowly under the synergetic effect of temperature and plastic strain.

During thermal cycling, not only very small spherical $\gamma^{\prime}$ precipitates, but also cuboid ones and even small rafts are regularly created and dissolved. According to the numbers given in Table 1, the precipitation kinetics were more rapid than the dissolution kinetics, since the surface fraction $\left(\mathrm{f}_{\mathrm{sR}}\right)$ and the number of rafts (through the variation of $\lambda$ ) was higher at the point $C$ than $A$. The low-temperature incursion during creep creates new rafts, but on the other hand thermal cycling enhances global $\gamma^{\prime}$ dissolution (overall raft surface fraction was always smaller in thermal cycling conditions versus isothermal) and thus accelerates the creep damage [37]. This 
to be submitted to Phil Mag.

apparent contradiction may be rationalised firstly by considering that imposing thermal cycling from the beginning of the creep hinders the stabilisation of numerous rafts and secondly by the synergetic effect between the microstructure evolution and creep strain. Indeed in superalloys the role of plastic strain, and the associated dislocation motion, on the transformation of the $\gamma^{\prime}$ microstructure has been repeatedly demonstrated either for formation of rafts [38] or for their destabilisation [32].

\subsection{Climb of $b=a<010>$ dislocations}

We reported in section 3.2.2 the presence of numerous dislocations within $\gamma^{\prime}$ rafts with a[010] Burgers vectors. This type of dislocation was the most frequent type observed after creep at the highest temperatures tested. Such a[010] dislocation has been mentioned in earlier reports, in single-phase $\mathrm{Ni}_{3} \mathrm{Al}$ compounds $[39,40]$ and in the $\gamma^{\prime}$ phase of the superalloy CMSX $2[11,12]$. More recently they have been repeatedly observed to cut $\gamma^{\prime}$ rafts after high-temperature low-stress creep experiments in various superalloys: CMSX 6 [13], SRR 99 [14],CMSX 4 [29], CMSX 10 [16], TMS-138 [20]. In the last studies in which such dislocations were reported, in superalloys NASAIR-100 [19] and LEK94 [18], the authors recognised that this $\gamma^{\prime}$ cutting by climbing a[100] dislocations is a generic recovery mechanism for hightemperature low-stress creep of superalloys. In line with these findings, we have shown that a similar mechanism also operates in MC2 superalloy, the activity of $\mathrm{a}[010]$ dislocations being enhanced by the testing temperature as reported in Table 3. A common feature to most of these observations, from the literature and from the present study, is the fact that a[010] dislocations move through a climb mechanism. It has been reported that the a[100] dislocations may dissociate forming either 
superpartial dislocations [29] or Shockley type partial dislocations involving stacking faults [41] similarly to the configurations studied in other $\mathrm{L1}_{2}$ compounds [42]. Such dissociation seems to stabilize the line orientation along $<101>$ directions, as observed in the present study, but does not strongly impact the motion mode which is still mainly climb. Even though to our knowledge, the sign of the climbing dislocation has never been determined, it is postulated that a[010] dislocations climb by absorbing vacancies which results in shrinking the specimen (a climbing process associated to the emission of vacancies would result in thickening the specimen in a direction perpendicular to the applied tensile stress, which is not realistic).

The driving force for the activation of a[010] dislocations has been questioned in the literature. Indeed when creep load is imposed along the [001] direction, the $\mathrm{a}[010]$ dislocations do not experience any resolved force (neither glide nor climb) from the applied stress. It is thus believed that their activation is related to a kind of secondary process that recovers the activation of a primary system which is actually driven by the applied stress and provides creep strain along [001]. Such recovery processes include i) the annihilation of $\gamma / \gamma^{\prime}$ interface dislocations when the a[010] dislocations have crossed the raft [19] and ii) the absorption of vacancies emitted by the climb of a primary system in the interface. Epishin and Link [16] were the first to show that such a mechanism is involved in the high-temperature creep strain of CMSX-4 and CMSX-10 superalloys. In their description, the creep strain along [001] is due to the transverse glide-climb of $\mathrm{a} / 2<011>$ dislocations, thus producing vacancies. These excess vacancies can be absorbed by pores and by $a<100>$ dislocations which implies their climb in $\gamma^{\prime}$ rafts. In turn, the crossing of rafts by $\mathrm{a}[100]$ dislocations annihilates interface dislocation, recovering the deformation mechanism in the $\gamma$ channels. Such a mechanism, involving two dislocation systems 
to be submitted to Phil Mag.

and vacancy exchange has been demonstrated to operate during compression testing of AlPdMn quasicrystals [21, 43]. The TEM observations reported here show that a similar mechanism must operate in the MC2 superalloy single crystal during hightemperature creep along the [001] axis.

This mechanism involves two dislocation systems: system 1 accounts for the longitudinal strain along the load direction and creates vacancies, and system 2 absorbs vacancies and produces shrinkage of the specimen normal to the load axis. Dislocation system 1 can ensure a steady-state macroscopic strain only in the case where the vacancies it creates are eliminated in some way. If not, the osmotic force due to the oversaturation of vacancies would block this deformation. The elimination of vacancies requires two main points: i) the existence of sinks for the vacancies, and ii) that the flux of vacancies to these sinks is fast enough compared to the strain rate. These two points may be rate limiting and the creep rate of rafted single-crystal superalloys could be controlled by the dislocations in $\gamma^{\prime}$ raft, either through their limited climb velocity [29] or limited density [30]. We recently calculated [44] the flux of vacancies generated by their diffusion between the $\gamma / \gamma^{\prime}$ interface (where an oversaturation is due to the activity of system 1 dislocations) and the centre of $\gamma^{\prime}$ rafts assumed to be at thermal equilibrium. The diffusion data show that for $\mathrm{T}=950^{\circ} \mathrm{C}$ and $1150^{\circ} \mathrm{C}$, this flux is more than large enough to ensure the transportation of vacancies from system 1 to system 2 and thus can ensure condition ii) as stated above. The thermal diffusion to pre-existing pores, which has been proposed as a alternative vacancy sink [16], was shown to be much more difficult since the distance to be travelled by the vacancies was in this case much larger than the raft thickness [44]. As speculated in the literature $[16,30]$, we may assume that the density of sinks, that is the density of system 2, climbing a[100] dislocations, may be the key point. This 
hypothesis is supported by our thermal cycling results. Indeed, during the thermal cycles the $\gamma^{\prime}$ phase repeatedly precipitates and dissolves. In particular, during the cooling step we show that small rafts are formed, their rafted shape indicates that they relaxed coherency stress, so they must be surrounded by a dislocation network for the compensation of $\gamma / \gamma^{\prime}$ misfit. Such a coarsened secondary precipitate, formed during anisothermal creep experiment - called micro-raft by the authors - has been indeed observed to be surrounded by dislocations, see Figure 12 in [10]. Upon heating, these rafts dissolve, we believe that the dislocations involved in the network are then released and pushed apart by the applied stress (stress is maintained during the whole cycle). By providing such fresh dislocations, the cooling step during thermal cycling allows an acceleration of the creep strain at the beginning of the high temperature dwell in the form of the primary stage, as observed in Figure 4 and in [6]. Once these dislocations are exhausted, the creep rate is lowered, leading to the secondary stage in the creep curve portion reported in Figure 4. Further support of the present conclusion on the predominant role of dislocation density in the $\gamma^{\prime}$ raft to be used as vacancy sinks is brought by the observation of samples crept at $950^{\circ} \mathrm{C}$. In these conditions, the $\gamma^{\prime}$ rafts are not dissolved, so no fresh dislocations are provided during creep, and a close examination of the crept microstructure reveals the presence of numerous loops inside the rafts, indicated by white arrows in Fig.11. The loops result from the coalescence of oversaturated vacancies, that could not be eliminated by climbing $\mathrm{a}[100]$ dislocations.

\section{Conclusions}

The creep behaviour of the MC2 single-crystal superalloy was studied at very high temperature, $950^{\circ} / 200 \mathrm{MPa}$ and $1150^{\circ} \mathrm{C} / 80 \mathrm{MPa}$ under both isothermal and thermal 
to be submitted to Phil Mag.

cycling conditions. It was shown that the thermal cycling strongly affects creep behaviour at $1150^{\circ} \mathrm{C}$ while no effect was observed at $950^{\circ} \mathrm{C}$, this was related to the partial dissolution of the $\gamma^{\prime}$ phase for the highest temperatures. Indeed for $1150^{\circ} \mathrm{C}$ testing, the thermal cycling during the creep test induces repeated precipitation and dissolution of $\gamma^{\prime}$ particles, as secondary precipitates but also as small rafts. This continuous modification of the precipitation microstructure during thermal cycles alters the raft morphology by reducing the overall surface ratio of the rafts and accelerating their degradation as compared to isothermal conditions.

The dislocation microstructures have been observed after interrupted isothermal and thermal cycling creep tests. The role of a[100] dislocations crossing the $\gamma^{\prime}$ rafts by a climbing process was revealed. This process acts as a recovery mechanism in regards to the dislocations responsible for the strain along the loading direction. This necessary recovery process could control the creep rate, however it seems that diffusion rate or dislocation climb velocity is fast enough and may not be rate limiting while the density of a[100] seems to be the crucial parameter. Thermal cycling creep, through the dissolution of $\gamma^{\prime}$ rafts formed during the low temperature incursion provides new dislocations which may explain the observed acceleration of the creep rate. 
to be submitted to Phil Mag.

\section{Tables}

Table 1: Quantitative characteristics of the rafted structure after creep at $1150^{\circ} \mathrm{C} / 80$ $\mathrm{MPa}$ in both isothermal and thermal cycling conditions. The surface fraction of the rafts $\left(f_{s R}\right)$, their mean thickness $(t)$ and the periodicity of the structure normal to the raft plane $(\lambda)$ are given.

Table 2: Diffraction vectors $-\mathbf{g}$ - and visibility of different dislocation segments shown in Figure 9, allowing their Burgers vector - b - determination. For each segment the line direction $-\xi$ - and the character $-\varphi-$ were determined by stereographic analysis. V: Visible, I: Invisible and RC: Residual Contrast.

Table 3 : Estimate of dislocation densities inside the $\gamma^{\prime}$ rafts separating dislocations with $\mathbf{b}=\mathrm{a}[010]$ and other types of dislocations, depending on the creep conditions. 
to be submitted to Phil Mag.

\section{Figure Captions}

Figure 1: Specimen temperature during thermal cycling creep experiments.

Interrupted tests were stopped at three different points: i) at the end of the hightemperature dwell - point $\mathrm{A}$; ii) at the low-temperature - point $\mathrm{B}$; iii) at the beginning of the high temperature dwell - point $\mathrm{C}$.

Figure 2: Specimen temperature showing the three different cooling rates (slow, fast and quench) used for interrupted tests.

Figure 3: Comparison of the creep curves obtained on isothermal and thermal cycling conditions for $950^{\circ} \mathrm{C} / 200 \mathrm{MPa}$ and $1150^{\circ} \mathrm{C} / 80 \mathrm{MPa}$.

Figure 4: Details of the creep strain during one cycle (only the high-temperature dwell is shown) showing the primary-secondary stages for creep performed at $1150^{\circ} \mathrm{C} / 80 \mathrm{MPa}$ (a) and linear dependence of strain versus time for $950^{\circ} \mathrm{C} / 200 \mathrm{MPa}$ (b).

Figure 5: Microstructures after creep at $950^{\circ} \mathrm{C} / 200 \mathrm{MPa}$ for isothermal (a) and thermal cycling (b) conditions.

Figure 6: Microstructures after creep at $1150^{\circ} \mathrm{C} / 80 \mathrm{MPa}$ for isothermal (a) and thermal cycling conditions. For the latter, tests were interrupted at different points of the thermal cycle, as indicated in Figure 1: point A, end of the $12^{\text {th }}$ high temperature dwell (b); point $\mathrm{B}$, low temperature point of the $12^{\text {th }}$ cycle (c) and point $\mathrm{C}$, beginning of the $13^{\text {th }}$ high temperature dwell (d).

Figure 7: Details of the $\gamma^{\prime}$ secondary precipitation during creep at $1150^{\circ} \mathrm{C}$ the images correspond to cycling creep specimen interrupted at the end of the high-temperature dwell - point $\mathrm{A}$ - (a) and at the low temperature point - B- (b). Note that both samples only differ by the cooling rate from $1150^{\circ} \mathrm{C}$ to room temperature: "quench" for A and "slow" for B, as in the curves in Figure 2.

Figure 8: Dislocation microstructures in a specimen crept at $950^{\circ} \mathrm{C} / 200 \mathrm{MPa}$ under thermal cycling conditions. Note dislocations (labelled 1 and 2) crossing or bowing into the $\gamma^{\prime}$ rafts and $\mathrm{a} / 2<110>$ type dislocations in the $\gamma$ corridors (labelled with $\mathrm{x}$ ).

Figure 9: Example of diffraction contrast images used to identify the Burgers vector of the dislocations observed in the $\gamma^{\prime}$ rafts. The corresponding specimen was crept at $1150^{\circ} \mathrm{C} / 80 \mathrm{MPa}$ under isothermal conditions to rupture. The dislocations are imaged in $\mathrm{BF}$ two beam conditions with different diffraction vectors in (a) and (b). The 
scheme in (c) illustrates the geometrical configuration of the dislocation segments $5,4,6$ (thick black line) together with the cubic unit directions $<100>$ (thin grey lines and cubes). The Burgers vector $b=a[010]$ of the dislocation is also indicated.

Figure 10: Overview of the dislocation microstructures in a specimen crept at $1150^{\circ} \mathrm{C} / 80 \mathrm{MPa}$ under thermal cycling conditions. The creep test was stopped at the low-temperature step of the thermal cycle (point B in Figure 2).

Figure 11: Detail of the dislocation microstructure in a specimen crept at $950^{\circ} \mathrm{C} / 200 \mathrm{MPa}$ under thermal cycling conditions - interrupted at low-temperature point of the thermal cycle - showing the presence of dislocation loops within the $\gamma^{\prime}$ rafts. 
to be submitted to Phil Mag.

\section{Acknowlegments}

The authors would like to thank the company Safran-Turbomeca for providing the materials studied and for financial support.

\section{References}

[1] F.R.N. Nabarro and H.L. De Villiers, The physics of creep. Taylor \& Francis, London, 1995.

[2] M. Feller-Kniepmeier and T. Link, Metallurgical Transactions, 20A (1989) p. 1233.

[3] T.M. Pollock and A.S. Argon, Acta Metallurgica and Materialia, 42 (1994) p. 1859.

[4] V. Sass and M. Feller-Kniepmeier, Materials Science and Engineering A, 245 (1998) p. 19.

[5] M. Kolbe, A. Dlouhy, and G. Eggeler, Materials Science and Engineering A, 246 (1998) p. 133.

[6] A. Raffaitin, D. Monceau, F. Crabos, and E. Andrieu, Scripta Materialia, 56 (2007) p. 277.

[7] A. Raffaitin, Influence du cyclage thermique sur les comportements en oxydation/corrosion et en fluage de systèmes MCrAlY/superalliage à base de nickel. PhD Thesis. Institut National Polytechnique de Toulouse.Toulouse: 2007.

[8] J. Cormier, X. Milhet, and J. Mendez, Journal of Materials Science, 42 (2007) p. 7780 .

[9] J. Cormier, X. Milhet, J.L. Champion, and J. Mendez, Advanced Engineering Materials, 10 (2008) p. 56.

[10] J.B. le Graverend, J. Cormier, M. Jouiad, F. Gallerneau, P. Paulmier, and F. Hamon, Materials Science and Engineering: A, 527 (2010) p. 5295.

[11] F. Louchet and M. Ignat, Acta Metallurgica, 34 (1986) p. 1681.

[12] R. Bonnet and A. Ati, Acta Metallurgica, 37 (1989) p. 2153.

[13] G. Eggeler and A. Dlouhy, Acta Materialia, 45 (1997) p. 4251.

[14] T. Link, A. Epishin, and U. Bruckner, Scripta Materialia, 39 (1998) p. 1463.

[15] T. Link, A. Epishin, M. Klaus, U. Bruckner, and A. Reznicek, Materials Science and Engineering A, 405 (2005) p. 254.

[16] A. Epishin and T. Link, Philosophical Magazine, 84 (2004) p. 1979.

[17] A. Kostka, G. Malzer, and G. Eggeler, Journal of Microscopy, 223 (2006) p. 295.

[18] A. Kostka, G. Malzer, G. Eggeler, A. Dlouhy, S. Reese, and T. Mack, Journal of Materials Science 42 (2007) p. 3951. 
[19] P.M. Sarosi, R. Srinivasan, G.F. Eggeler, M.V. Nathal, and M.J. Mills, Acta Materialia, 55 (2007) p. 2509.

[20] J.X. Zhang, H. Harada, and Y. Koizumi, Journal of Materials Research, 21 (2006) p. 647.

[21] F. Mompiou and D. Caillard, Acta Materialia, 56 (2008) p. 2262.

[22] F. Mompiou and D. Caillard, Materials Science and Engineering A, 483 - 484 (2008) p. 143.

[23] S. Dryepondt, D. Monceau, F. Crabos, and E. Andrieu, Acta Materialia, 53 (2005) p. 4199.

[24] ImageJ. software available at http://rsbweb.nih.gov/ij/

[25] F. Touratier, Etude des mécanismes de déformation et d'endommagement du superalliage base nickel MC2 en fluage aux très hautes températures. $\mathrm{PhD}$ Thesis, Institut National Polytechnique. Université de Toulouse.Toulouse: 2008.

[26] T. Grosdidier, A. Hazotte, and A. Simon, Materials Science and Engineering A, 256 (1998) p. 183.

[27] A.M. Brass, D. Roux, and J. Chêne, Materials Science and Engineering A, 323 (2002) p. 97.

[28] J. Cormier, X. Milhet, and J. Mendez, Acta Materialia, 55 (2007) p. 6250.

[29] R. Srinivasan, G.F. Eggeler, and M.J. Mills, Acta Materialia, 48 (2000) p. 4867.

[30] L.J. Carroll, Q. Feng, and T.M. Pollock, Metallurgical and Materials Transactions A, 39 (2008) p. 1290.

[31] A. Dlouhy, R. Schaublin, and G. Eggeler, Scripta Materialia, 39 (1998) p. 1325 .

[32] F. Touratier, E. Andrieu, D. Poquillon, and B. Viguier, Mater. Sci. Eng. AStruct. Mater. Prop. Microstruct. Process., 510-11 (2009) p. 244.

[33] R.C. Reed, D.C. Cox, and C.M.F. Rae, Materials Science and Engineering: A, 448 (2007) p. 88.

[34] K. Serin, G. Gobenli, and G. Eggeler, Materials Science and Engineering A, 387-389 (2004) p. 133.

[35] T. Grosdidier, A. Hazotte, and A. Simon, Scripta Metallurgica et Materialia, 30 (1994) p. 1257.

[36] M. Hantcherli, B. Viguier, F. Pettinari- Sturmel, J. Douin, and A. Coujou, to be published, (2011).

[37] R. Goti, B. Viguier, and F. Crabos, to be published (2011).

[38] M. Veron, Y. Brechet, and F. Louchet, Scripta Materialia, 34 (1996) p. 1883.

[39] P. Veyssiere and J. Douin, Philosophical Magazine, 51 (1985) p. L1.

[40] N.L. Baluc, Contribution à l'étude des défauts et de la plasticité d'un composé intermetallique ordonné : Ni3Al. PhD Thesis, Ecole Polytechnique Fédérale.Lausanne: 1990.

[41] C. Kohler, T. Link, and A. Epishin, Philosophical Magazine, 86 (2006) p. 5103.

[42] J. Bonneville and G. Vanderschaeve, Philos. Mag. Lett., 78 (1998) p. 87.

[43] F. Monpiou, L. Bresson, P. Cordier, and D. Caillard, Philosophical Magazine, 83 (2003) p. 3133.

[44] F. Touratier, B. Viguier, C. Siret, S. Lesterlin, and E. Andrieu, Advanced Materials Research 278 (2011) p 7. 


\begin{tabular}{|c|l|c|c|c|}
\hline \multicolumn{2}{|c|}{ Creep condition and interruption point } & $\mathrm{f}_{\mathrm{sR}}(\%)$ & $\mathrm{t}(\mathrm{nm})$ & $\lambda(\mathrm{nm})$ \\
\hline \multirow{2}{*}{\begin{tabular}{l} 
Isothermal \\
\multirow{3}{*}{$\begin{array}{l}\text { Thermal } \\
\text { cycling }\end{array}$}
\end{tabular}} & End of dwell (A) & $46 \pm 3$ & $410 \pm 35$ & $560 \pm 20$ \\
\cline { 2 - 5 } & Low temperature state (B) & $47 \pm 1$ & $400 \pm 20$ & $690 \pm 15$ \\
\cline { 2 - 5 } & Beginning of dwell (C) & $42 \pm 5$ & $410 \pm 25$ & $805 \pm 20$ \\
\hline
\end{tabular}




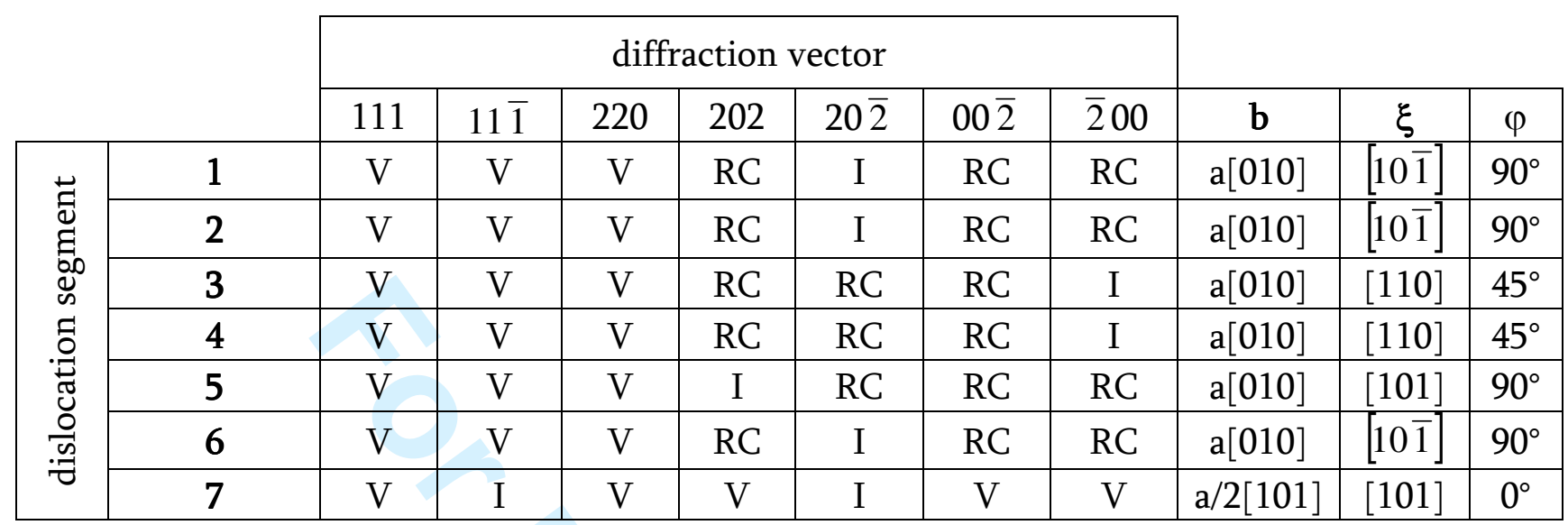




\begin{tabular}{|c|c|c|c|}
\hline Creep conditions & $\begin{array}{c}\mathrm{b}=\mathrm{a}[\mathbf{0 1 0}] \\
\mathrm{density}\left(\mathrm{m}^{-2}\right)\end{array}$ & $\begin{array}{c}\text { Other dislocations } \\
\text { density }\left(\mathbf{m}^{-2}\right)\end{array}$ & $\begin{array}{c}\text { Ratio of } \\
\text { dislocation } \\
\text { density }\end{array}$ \\
\hline $950^{\circ} \mathrm{C} / 200 \mathrm{MPa}$ Isothermal & $0.6610^{12}$ & $0.4210^{12}$ & 1.6 \\
\hline $950^{\circ} \mathrm{C} / 200 \mathrm{MPa}$ Thermal cycling, point $\mathrm{B}$ & $1.6410^{12}$ & $2.0510^{12}$ & 0.8 \\
\hline $1150^{\circ} \mathrm{C} / 80 \mathrm{MPa}$ Isothermal & $1.4510^{12}$ & $0.6610^{12}$ & 2.2 \\
\hline $1150^{\circ} \mathrm{C} / 80 \mathrm{MPa}$ Thermal cycling, point B & $1.5910^{12}$ & $0.2210^{12}$ & 7.2 \\
\hline
\end{tabular}




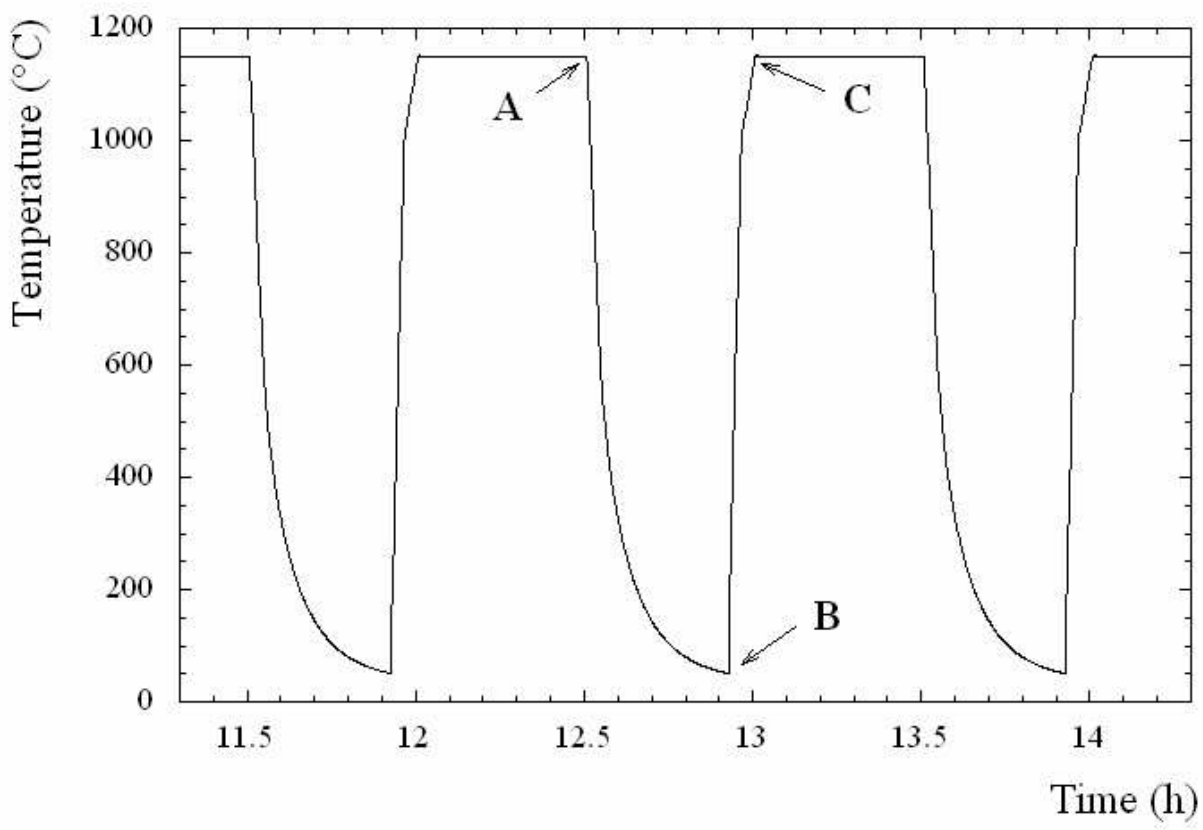

$256 \times 174 \mathrm{~mm}(72 \times 72 \mathrm{DPI})$ 


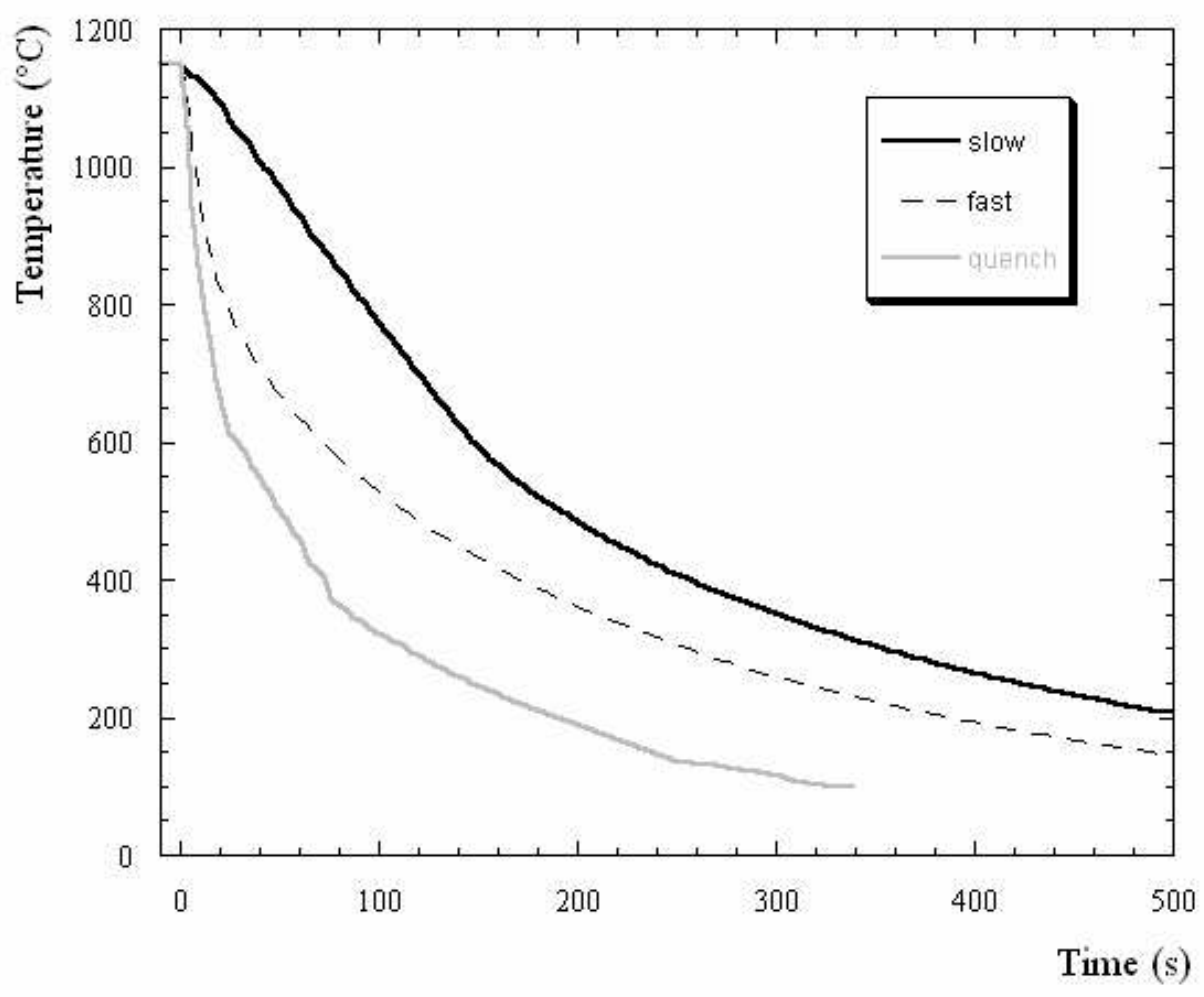

$208 \times 173 m m(72 \times 72$ DPI $)$ 


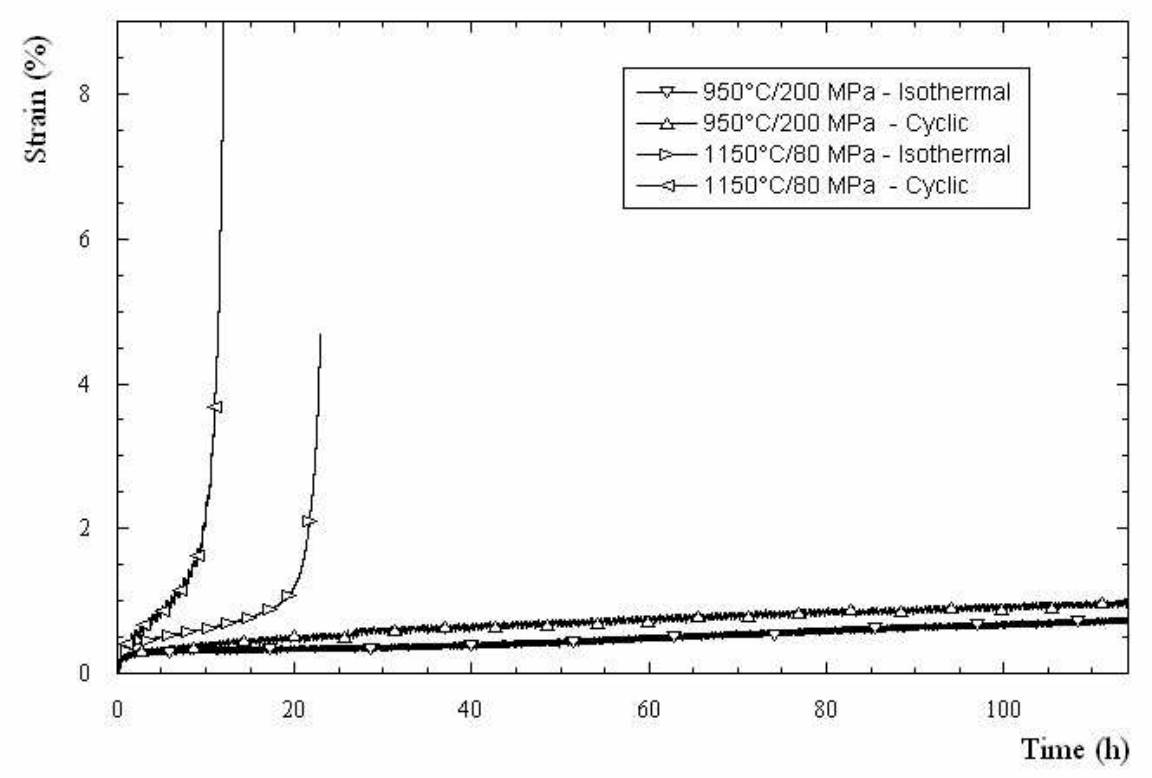

$264 \times 174 \mathrm{~mm}(72 \times 72$ DPI $)$ 


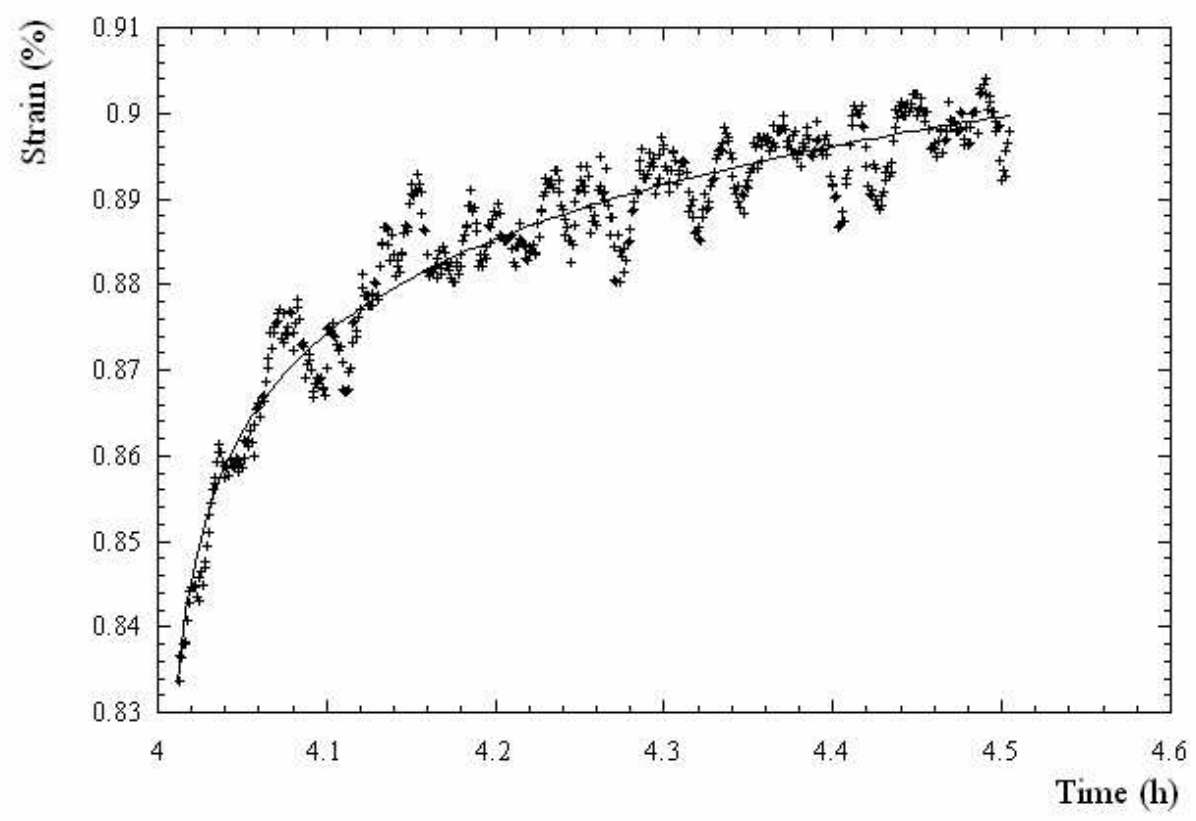

$233 \times 162 \mathrm{~mm}(72 \times 72 \mathrm{DPI})$

http://mc.manuscriptcentral.com/pm-pml 


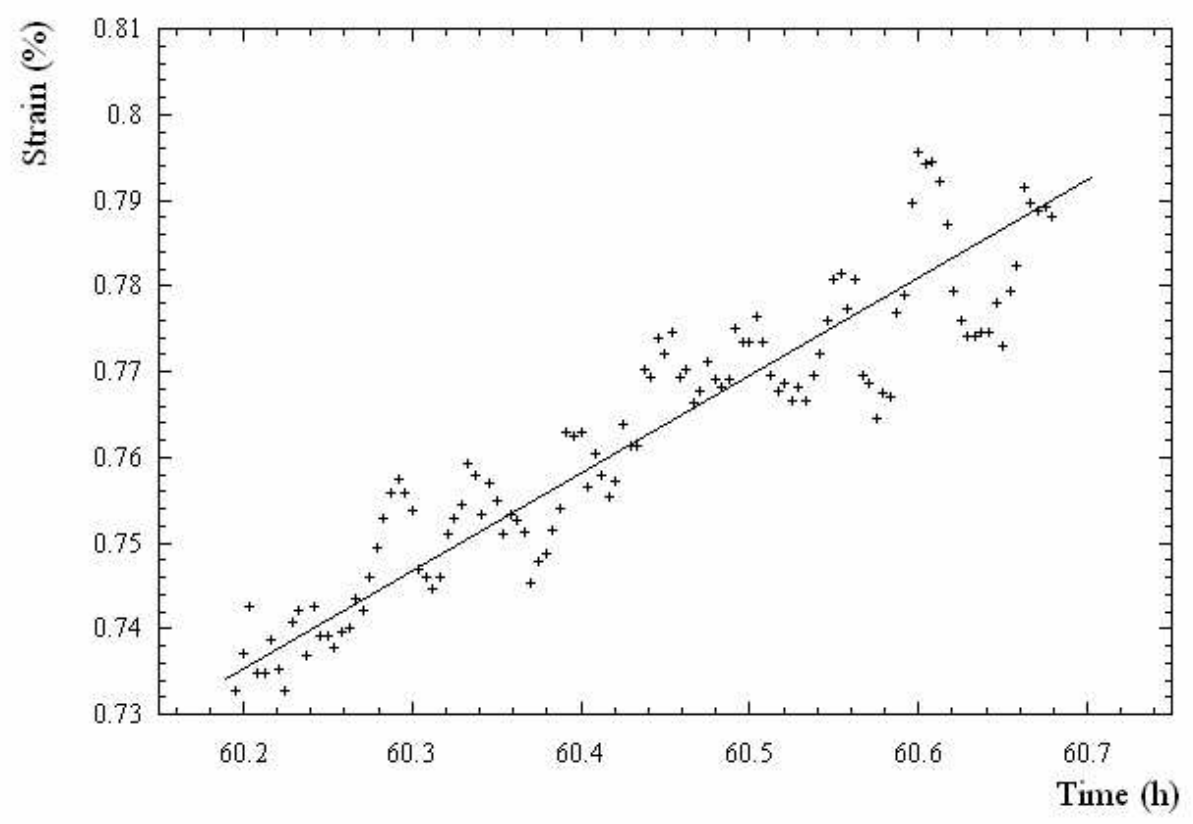

$233 \times 162 \mathrm{~mm}(72 \times 72 \mathrm{DPI})$

1

2

3

4

5

6

9

10

11

12

13

14

16

17

18

19

20

21

23

24

25

26

27

28

29

34

35

36

37

38

39

40

41

42

43

44

45

46

47

48

49

50

51

52

53

54

55

56

57

58

59

60

http://mc.manuscriptcentral.com/pm-pml 


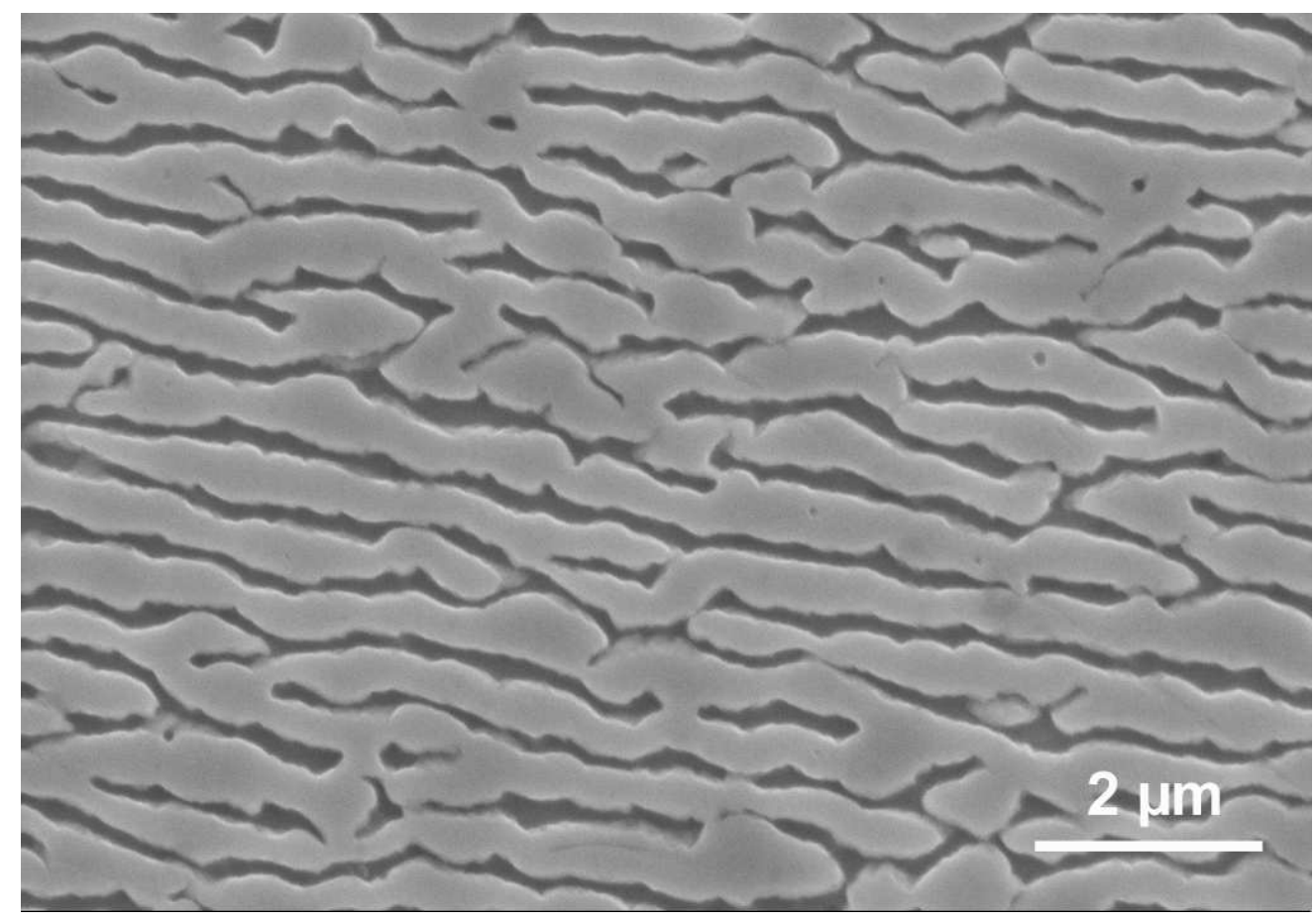

$173 \times 120 \mathrm{~mm}(150 \times 150 \mathrm{DPI})$ 


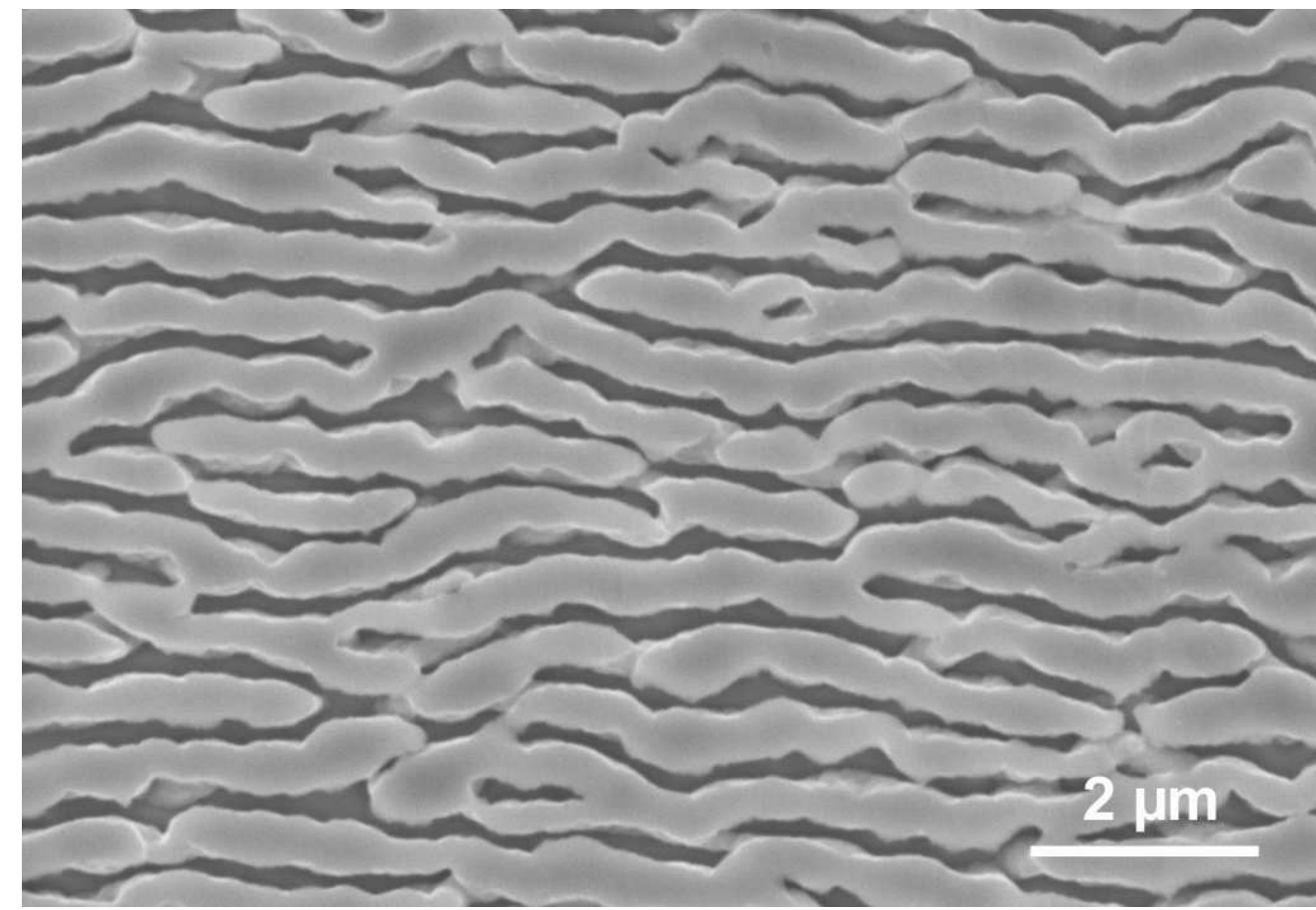

$173 \times 120 \mathrm{~mm}(150 \times 150 \mathrm{DPI})$ 


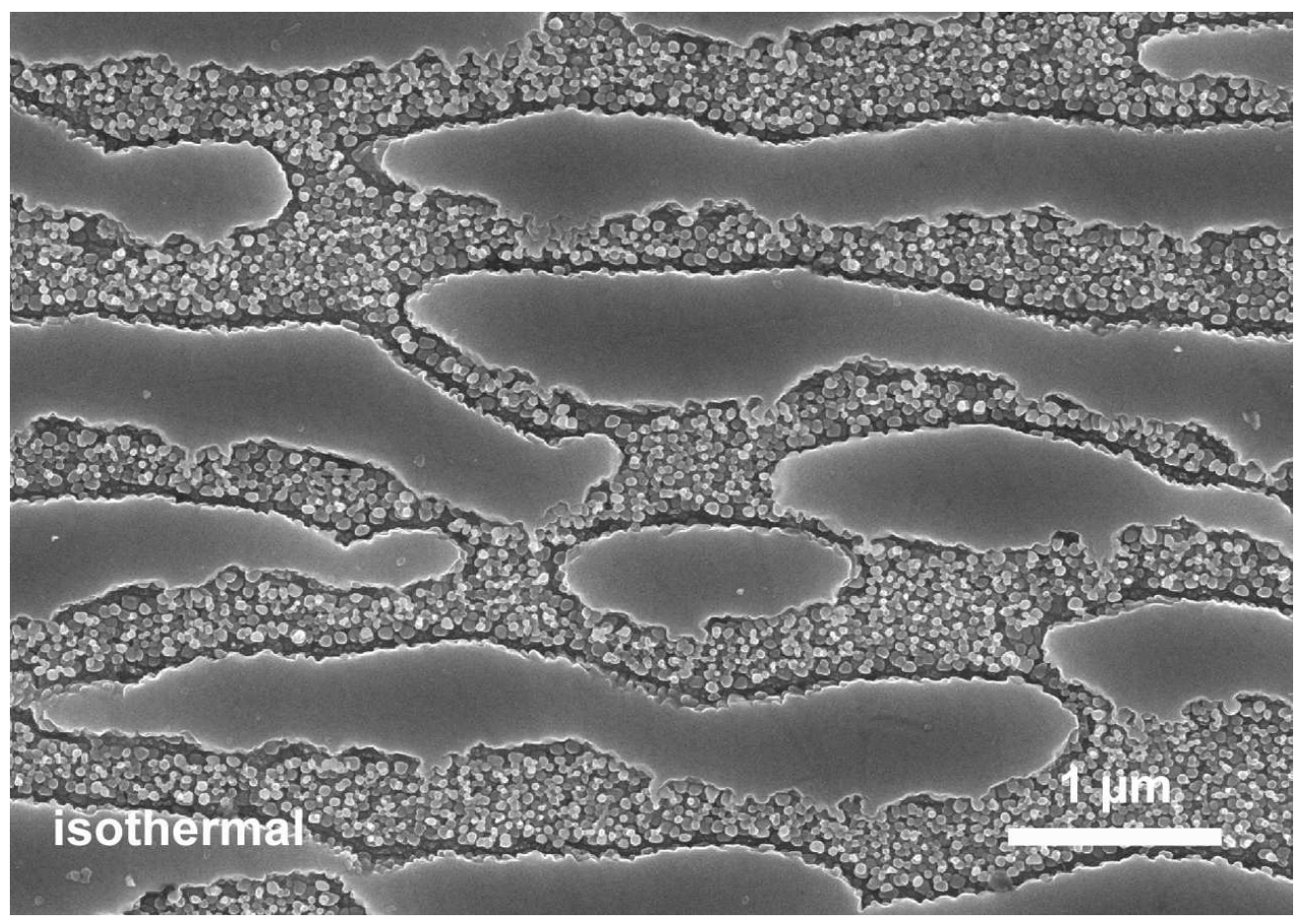

$216 \times 152 \mathrm{~mm}(150 \times 150 \mathrm{DPI})$

$216 \times 152 \mathrm{~mm}(150 \times 150 \mathrm{DPI})$ 


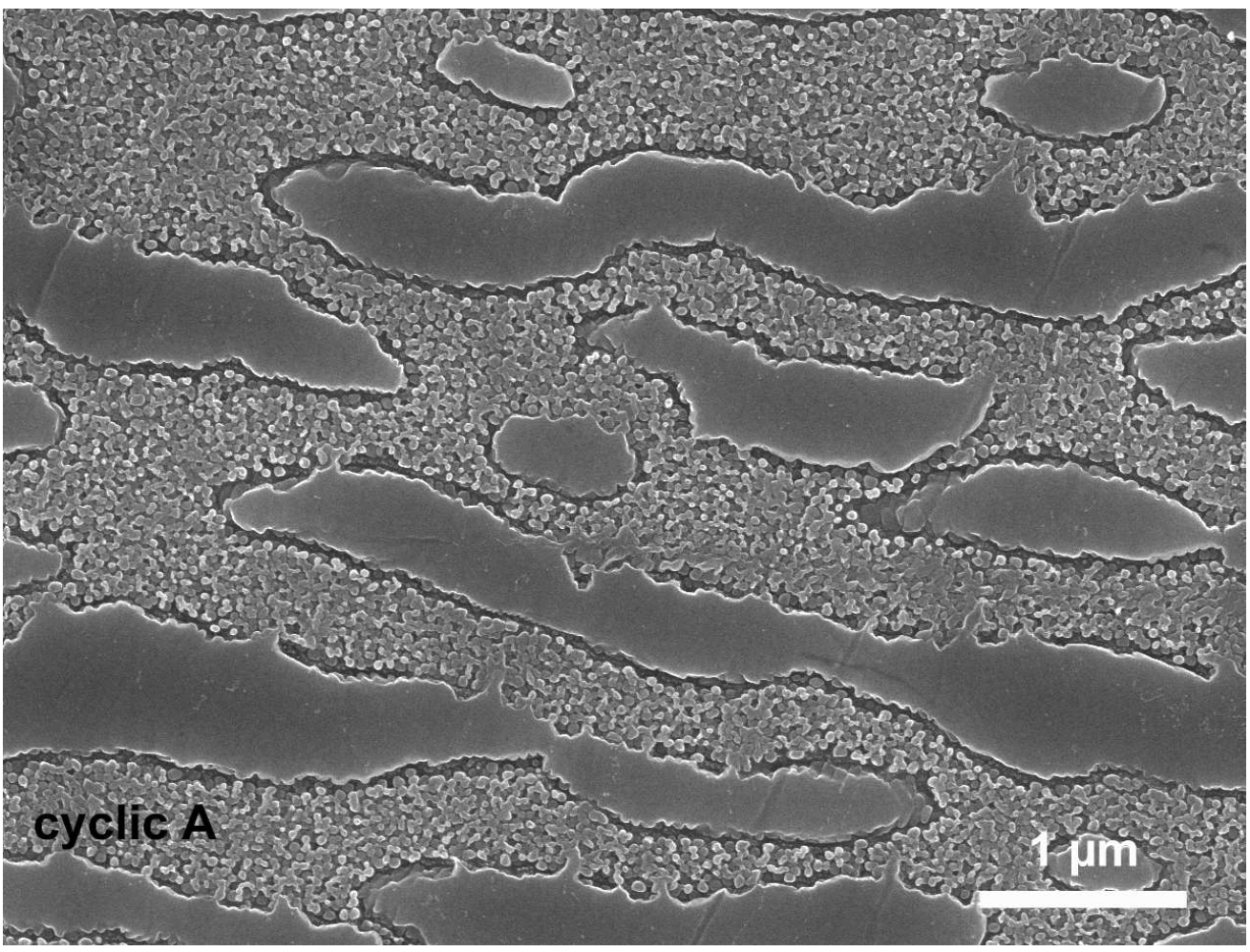

$216 \times 163 \mathrm{~mm}(150 \times 150 \mathrm{DPI})$ 


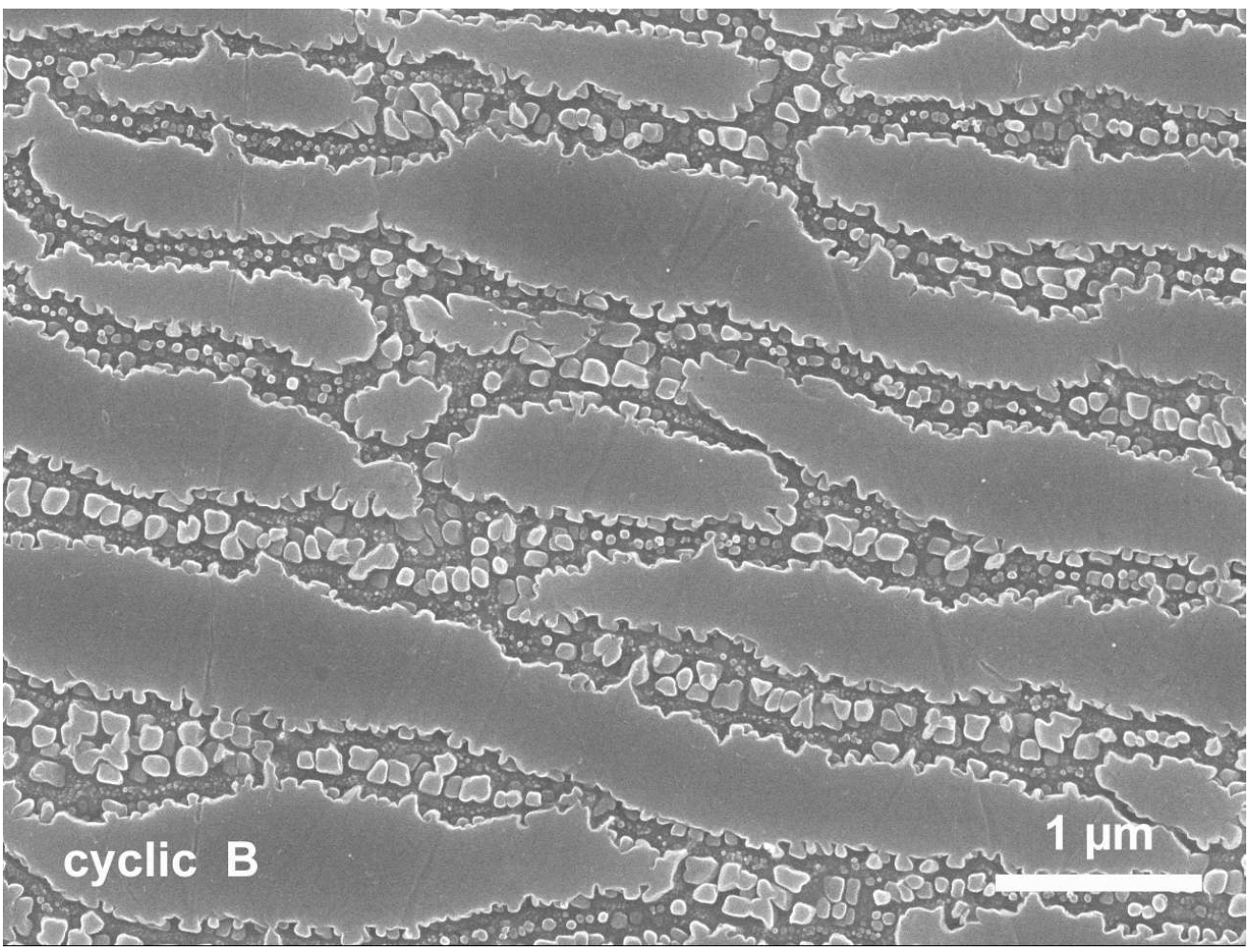

$216 \times 163 \mathrm{~mm}(150 \times 150 \mathrm{DPI})$ 


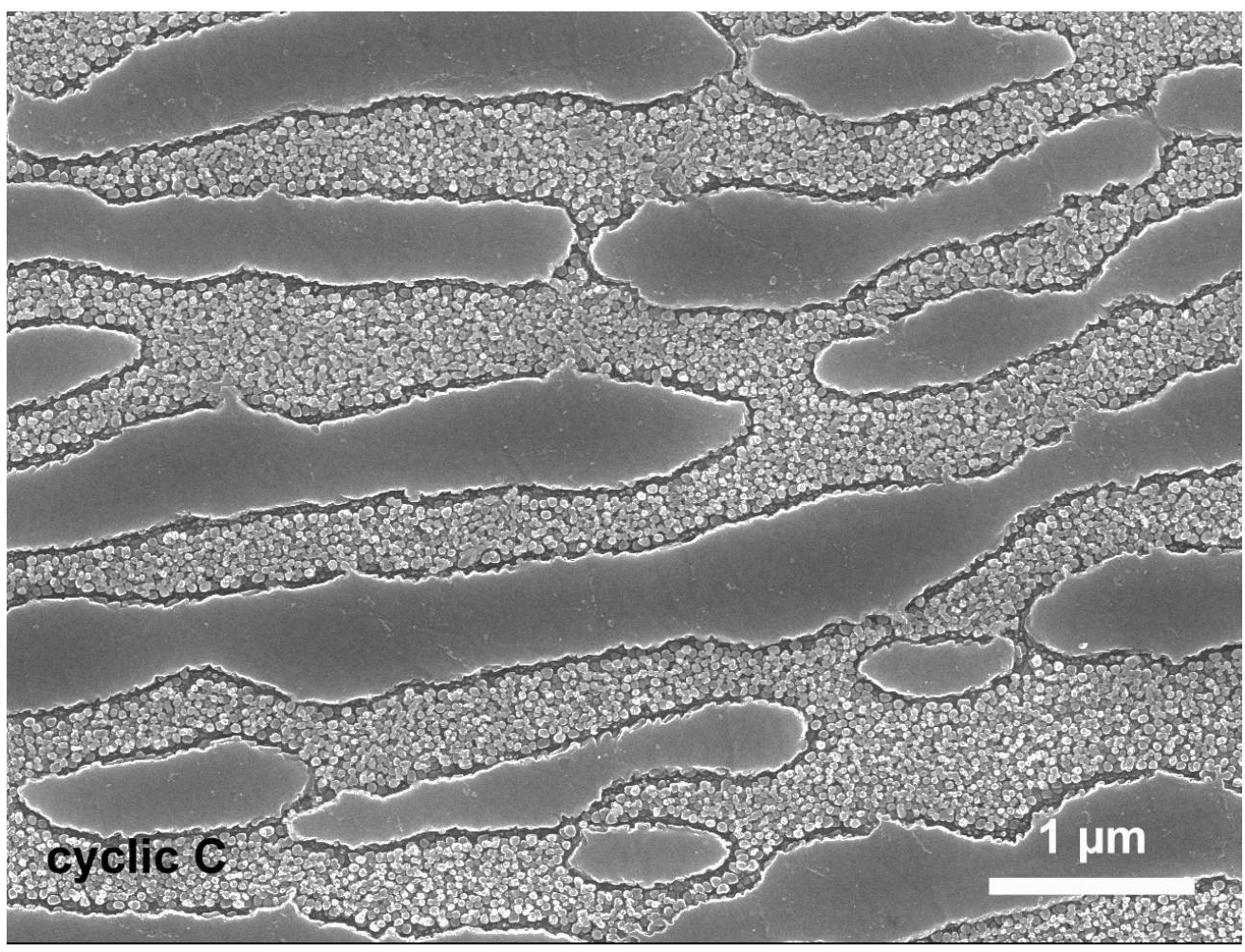

$216 \times 163 \mathrm{~mm}(150 \times 150 \mathrm{DPI})$ 


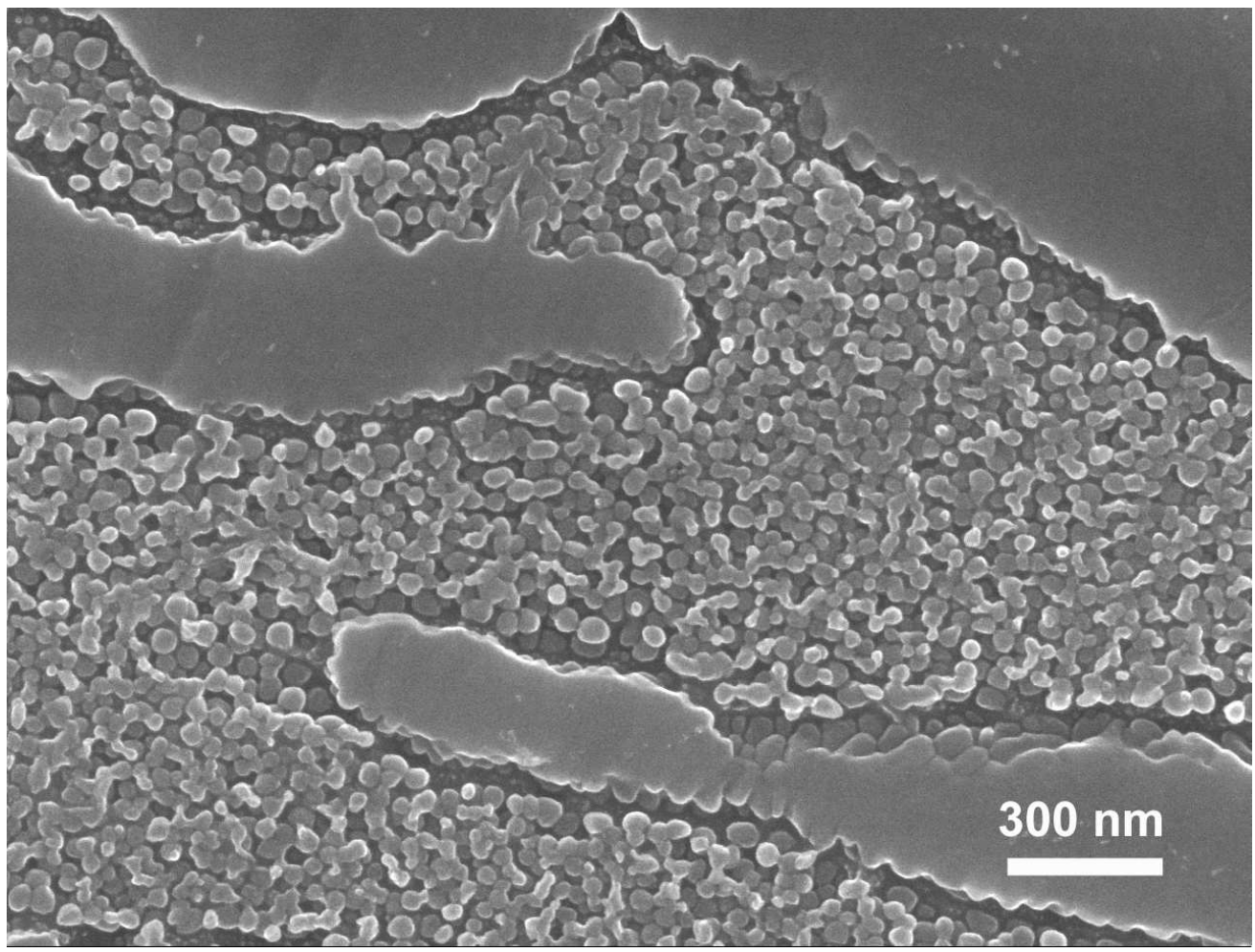

$216 \times 163 \mathrm{~mm}(150 \times 150 \mathrm{DPI})$ 


1
2
3
4
5
6
7
8
9
10
11
12
13
14
15
16
17
18
19
20
21
22
23
24
25
26
27
28
29
30
31
32
33
34
35
36
37
38
39
40
41
42
43
44
45
46
47
48
49
50
51
52
53
54
55
56
57
59
60

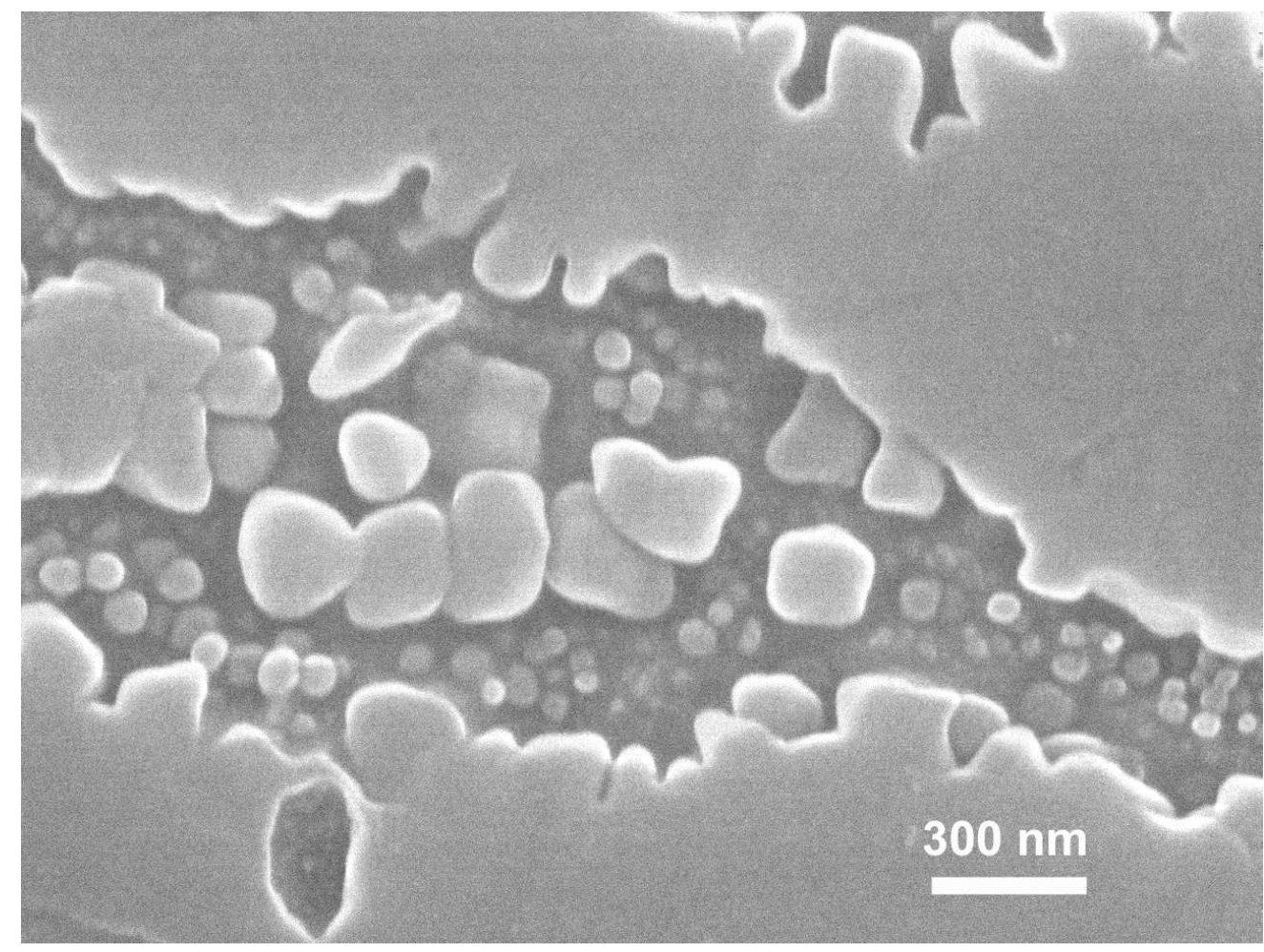

$216 \times 162 \mathrm{~mm}(150 \times 150 \mathrm{DPI})$ 


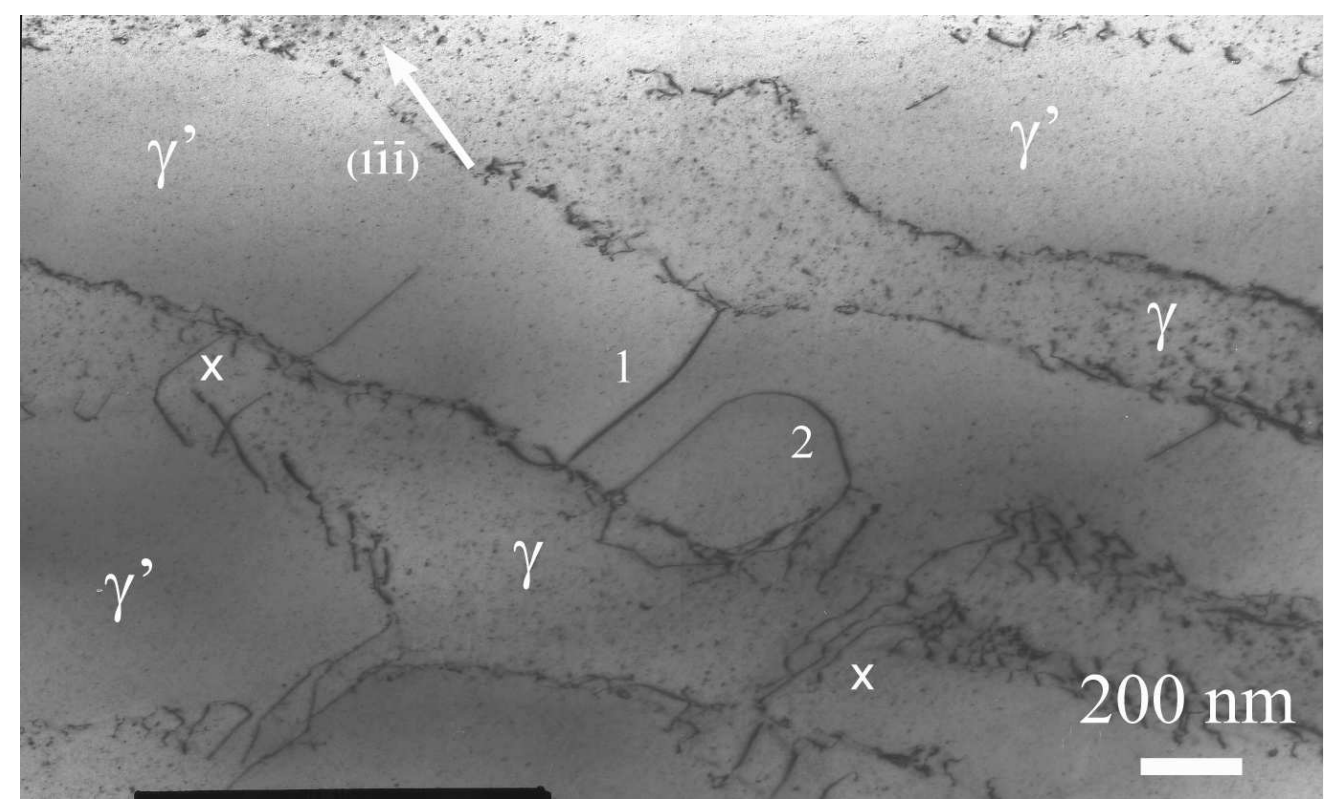

$230 \times 139 m m(150 \times 150$ DPI $)$ 


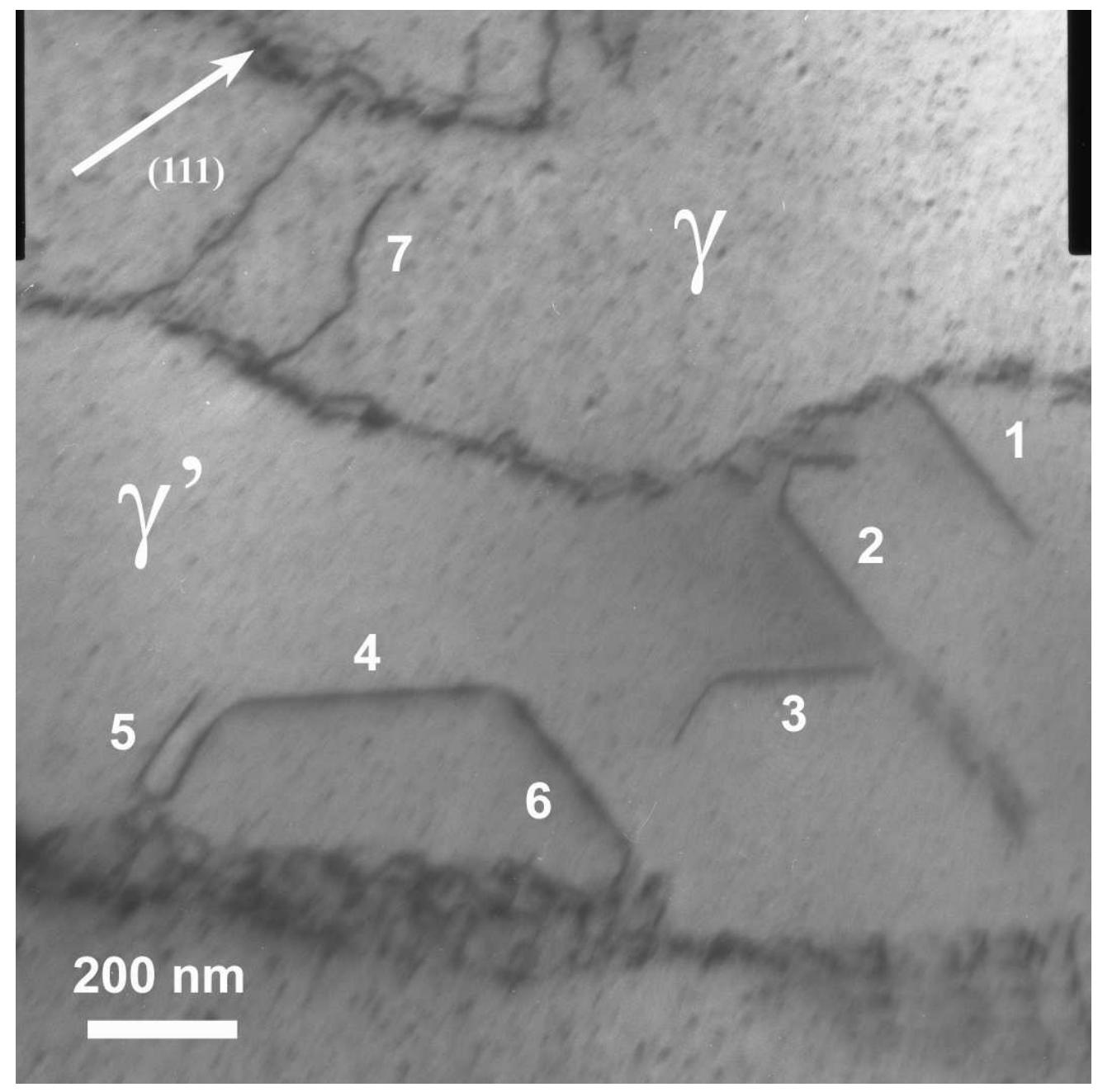

$180 \times 179 \mathrm{~mm}(150 \times 150 \mathrm{DPI})$ 


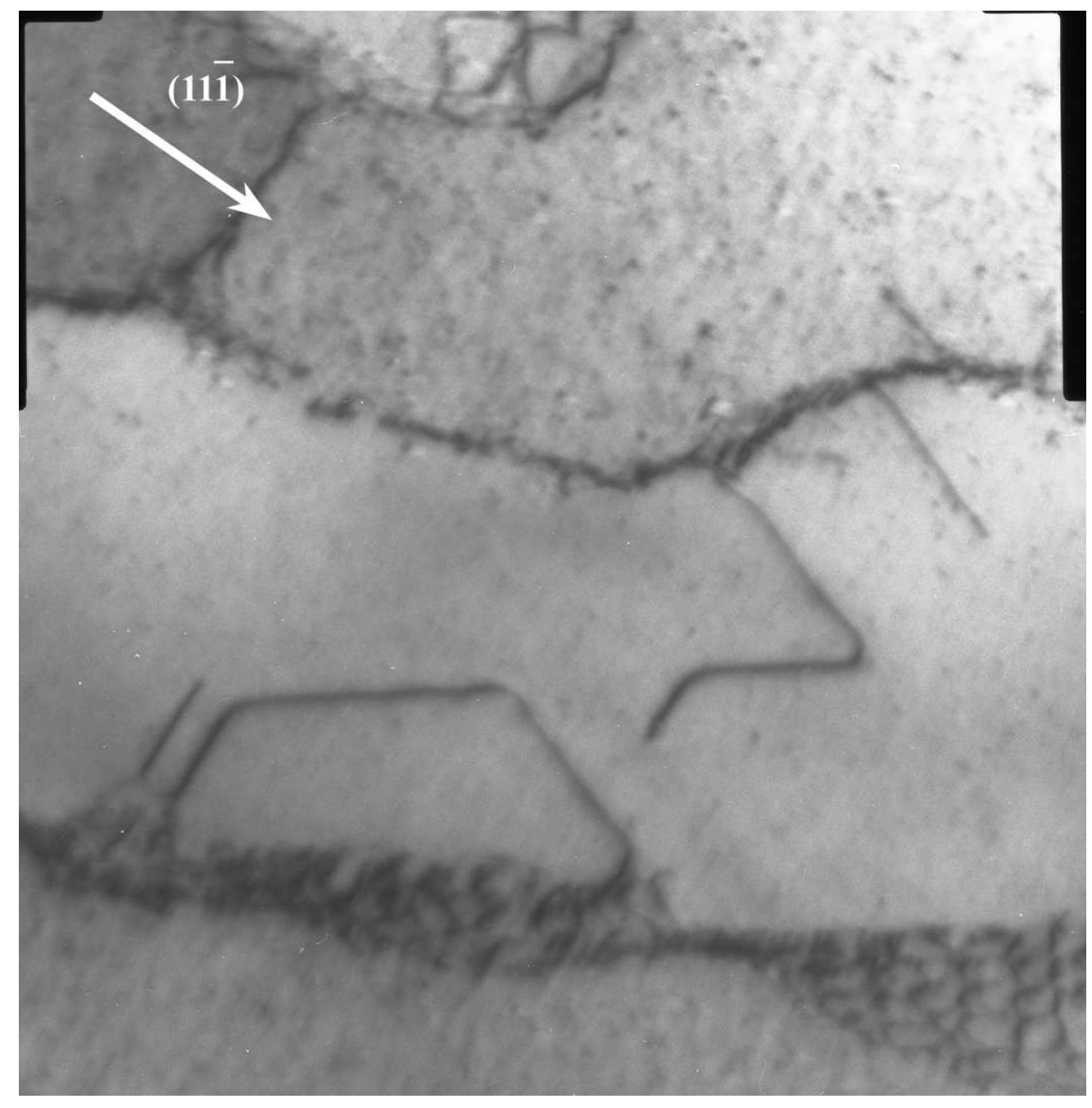

$180 \times 182 \mathrm{~mm}(150 \times 150 \mathrm{DPI})$ 


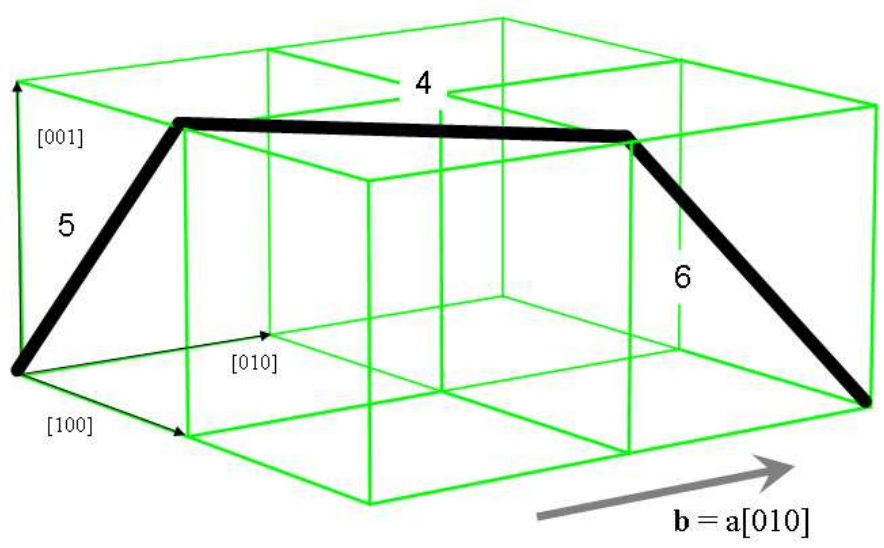

$254 \times 190 \mathrm{~mm}(96 \times 96 \mathrm{DPI})$ 


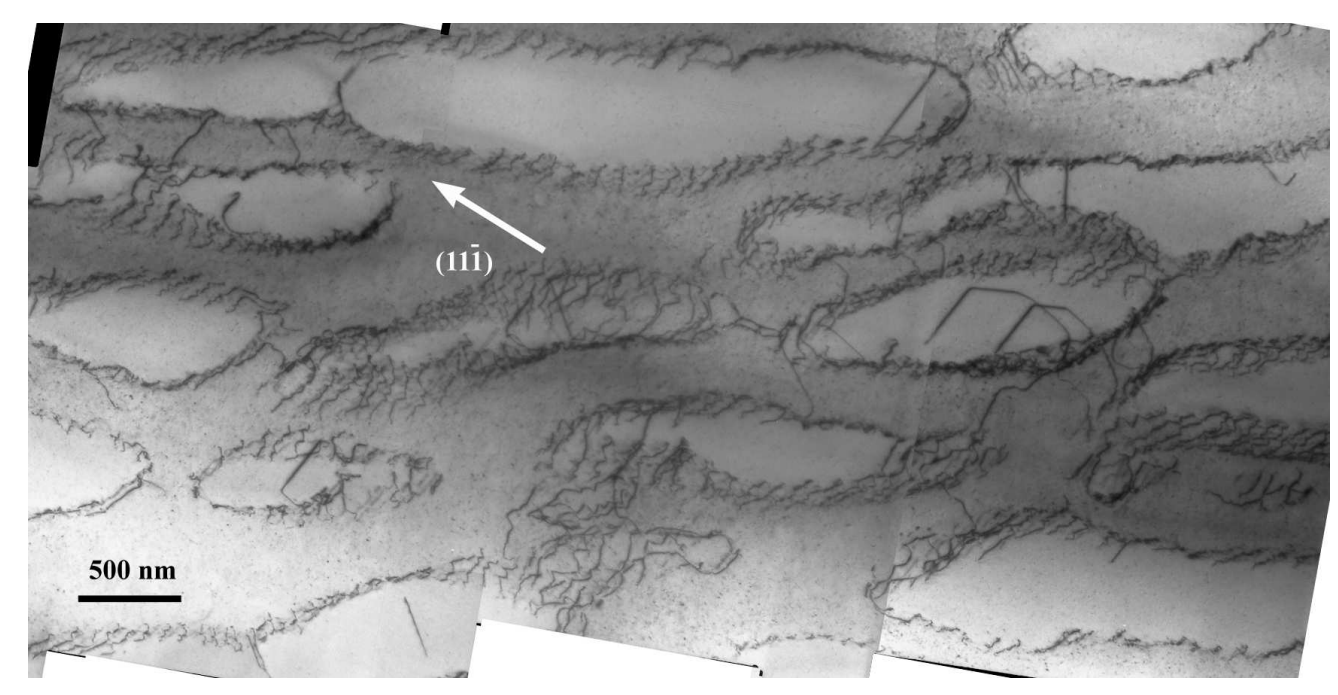

$293 \times 147 \mathrm{~mm}(150 \times 150 \mathrm{DPI})$ 


1
2
3
4
5
6
7
8
9
10
11
12
13
14
15
16
17
18
19
20
21
22
23
24
25
26
27
28
29
30
31
32
33
34
35
36
37
38
39
40
41
42
43
44
45
46
47
50
58
59
50
52
53
50

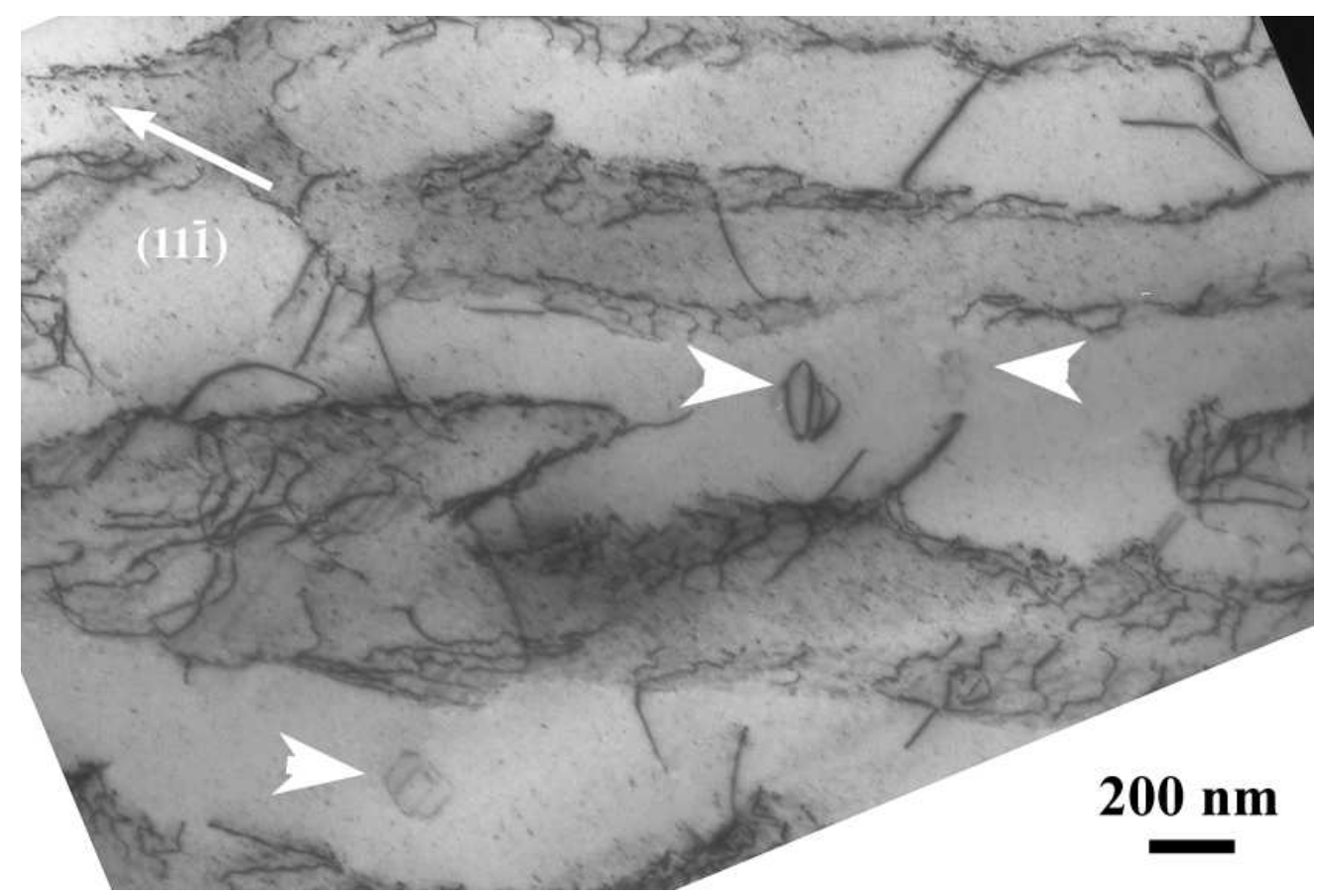

$141 \times 96 \mathrm{~mm}(150 \times 150 \mathrm{DPI})$ 